Portland State University

PDXScholar

$12-2018$

\title{
Environmental and Equity Scenarios for Alternative Fuel Vehicle Ownership and Use in the Portland Region
}

John MacArthur

Portland State University, macarthur@pdx.edu

Kelly Clifton

Portland State University, kclifton@pdx.edu

Joseph Broach

Portland State University, jbroach@pdx.edu

Baxter Shandobil

Portland State University

Follow this and additional works at: https://pdxscholar.library.pdx.edu/trec_reports

Part of the Transportation Commons, and the Urban Studies Commons Let us know how access to this document benefits you.

\section{Recommended Citation}

MacArthur, J., Clifton, K., Broach, J., Shandobil, B. Environmental and Equity Scenarios for Alternative Fuel Vehicle Ownership and Use in the Portland Region. TREC-RR-1167. Portland, OR: Transportation Research and Education Center (TREC), 2018. https://doi.org/10.15760/trec.215

This Report is brought to you for free and open access. It has been accepted for inclusion in TREC Final Reports by an authorized administrator of PDXScholar. Please contact us if we can make this document more accessible: pdxscholar@pdx.edu. 
FINAL REPORT

Environmental and Equity Scenarios for Alternative Fuel Vehicle Ownership and Use in the Portland Region

\section{TREC-RR-1167 D December 2018}

TREC is the Transportation Research and Education Center at Portland State University.

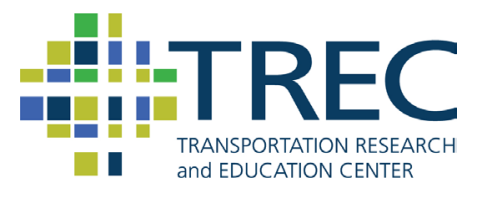




\section{Environmental and Equity Scenarios for Alternative Fuel Vehicle Ownership and Use in the Portland Region}

John MacArthur

Kelly Clifton, Ph.D.

Joseph Broach, Ph.D.

Baxter Shandobil

\section{Portland State

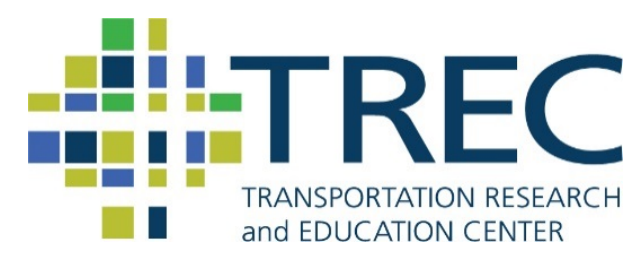

Final Report

December 2018 


\section{ACKNOWLEDGEMENTS}

This project was funded through a grant from Portland State University's Institute for Sustainable Solutions (ISS). The authors would like to especially thank Ingrid Fish (City of Portland Bureau of Planning and Sustainability) and Beth Gilden (ISS) for their valuable input, resources and support during the project to make sure it was successful.

\section{DISCLAIMER}

The contents of this report reflect the views of the authors, who are solely responsible for the facts and the accuracy of the material and information presented herein. The contents do not necessarily reflect the official views of the City of Portland. This report does not constitute a standard, specification, or regulation. 


\section{Table of Contents}

Overview..... .5

Research Questions..................................................................................6

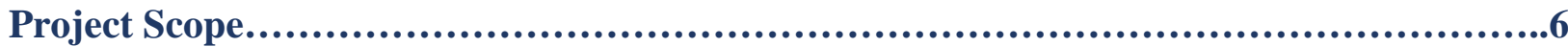

Data.........................................................................................6

Existing Conditions..................................................................................7

Research Approach........................................................................6

Data Preparation and Cleaning.....................................................6

VMT Calculations...................................................................7

Equity Determination.......................................................................8

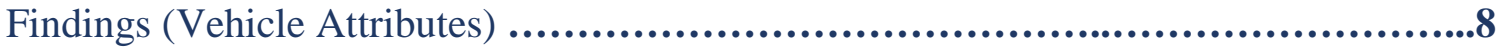

Vehicle Age.........................................................................9

Fuel Economy..................................................................10

Hybrids and EVs.................................................................12

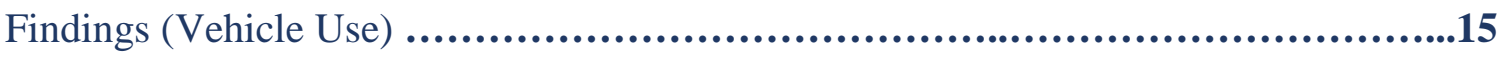

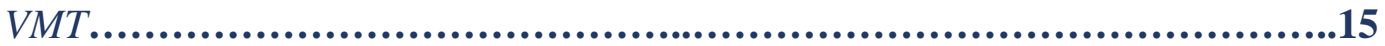

Fuel Consumption.................................................................17

Key Takeaways............................................................................18

VMT Model....................................................................................19

Research Approach................................................................................19

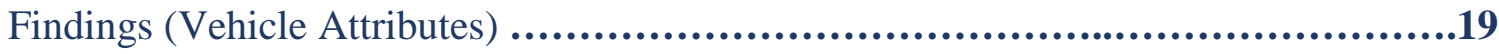

VMT by Fuel Type..............................................................19

VMT by Vehicle Age.............................................................19

Findings (Sociodemographic Attributes) .............................................21

Sociodemographics, Household Location, and VMT.............................21

Household Income and Vehicle Age...............................................21

Household Income and Fuel Economy.........................................22

Policy Scenarios.................................................................................24 
Methods.......................................................................................24

Policy Scenario Outcomes................................................................25

Costs/Benefits.......................................................................29

Key Takeaways............................................................................30

References................................................................................31

Appendix A...............................................................................32

Appendix B..............................................................................33

Appendix C..............................................................................34

Appendix D...........................................................................35

Appendix E..............................................................................................36 


\section{Overview}

There is a consensus within the scientific community that the burning of fossil fuels has increased the amount of greenhouse gasses such as carbon dioxide $\left(\mathrm{CO}_{2}\right)$ that are released into the atmosphere and is the primary cause of global climate change (1). Portland has been a leader amongst municipalities in addressing what will likely remain one of the biggest challenges facing humanity throughout the $21^{\text {st }}$ Century (2). Despite being the first city in the United States to enact a local plan of action for reducing carbon emissions, the air quality in Portland remains relatively poor, earning grades of “ $C$ ” and “ $D$ ” for high ozone days and 24-hour particulate pollution, respectively, and ranking as the 32nd worst metro area for particulate spikes $(3,4)$. The City of Portland is developing efforts to stay on track to meet the Climate Action Plan's goal of an 80 percent reduction in carbon emissions below 1990 levels by 2050 (2). At the same time, Portland recognizes the importance of making sure policies to meet environmental goals also consider equity impacts. The Portland Climate Action Plan states that currently "the many economic and health benefits of carbon reduction investments are not shared equitably across the city” (2).

The transportation sector is responsible for 25 percent of greenhouse gas emissions in the Portland metropolitan region, 14 percent of which is comprised of emissions from cars and light trucks (5). For Multnomah County, the transportation sector makes up 44 percent of greenhouse gas emissions based on the city and county's use of the ClearPath ICLEI Tool. Electric vehicles (EVs) ${ }^{1}$ and hybrid electric vehicle (HEVs), which are often considerably more efficient than internal combustion engine (ICE) vehicles, may have the potential to reduce the carbon footprint of automobile travel. Vehicle manufacturers are slowly but steadily rolling out new electric models. At the same time, Portland is struggling to determine where to prioritize the installation of EV charging infrastructure, a critical link to widespread adoption of EVs. Owners of EVs and HEVs, like most early adopters of new technologies, are largely high-income earners (6). Many EVs and HEVs carry a price premium over comparable ICE vehicles powered by fossil fuels and likely are not often within reach of most low-income consumers. Thus, the direct benefits of these technological advances are likely to accrue to these disadvantaged populations much later in the technological diffusion cycle, if at all.

The question for policy makers is: are these two ends - mitigation of climate impacts from transportation sources and promoting equitable access to efficient and clean mobility - at odds with one another or can both of these goals be achieved through one coordinated strategy? This research shows with targeted investments in underserved and income communities in Portland to increase the number of alternative vehicles, you can achieve these goals.

\footnotetext{
${ }^{1}$ Electric vehicles (EVs) means both battery electric vehicles and plug-in hybrid electric vehicles.
} 


\section{Research Questions}

- How are carbon impacts from the use of personal vehicles distributed among different neighborhoods in Portland and the Metro region?

- Do low-income and minority communities have a greater contribution to carbon emissions than the rest of Portland?

- What is the potential for different policy interventions to address carbon emissions from the transportation sector?

\section{Project Scope}

With a focus on equity, this analysis first establishes the current characteristics and usage patterns of personal vehicles in the Portland metro region. Next, we develop a statistical model of vehicle miles traveled (VMT) as a function of vehicle, household, and land-use characteristics. The VMT model allows us to predict the miles a given vehicle might be driven under various conditions. Finally, we use the model to present hypothetical policy scenarios in which portions of the existing personal vehicle fleet are replaced with either hybrid or electric vehicles and estimate the societal benefits that would result from the fuel saved under such a program.

\section{Data}

The data used in this analysis come from six key sources:

- Oregon Department of Motor Vehicles (DMV): supplied a vehicle census for the Portland region

- Oregon Department of Environmental Quality (DEQ): supplied a vehicle attributes table as well as odometer readings from emissions testing

- 2017 National Household Travel Survey (NHTS): included the linked household and vehicle VMT data to develop a mileage model

- U.S. Environmental Protection Agency (EPA): produces fuel efficiency estimates by vehicle

- American Community Survey (ACS) 2016 5-year estimates: provide estimated household characteristics based on vehicle registration location

- Metro, the regional metropolitan planning organization: maintains regional boundary files, a high accuracy geocoding database, and parcel-level land use information 


\section{Existing Conditions}

\section{RESEARCH APPROACH}

\section{Data Preparation and Cleaning}

First, the information from the DMV and DEQ datasets were combined and geocoded to represent what is, in theory, the entire universe of personal vehicle ownership and use for the region. The dataset provided by Oregon DMV contains the unique VIN of every vehicle registered in the Portland metro region, along with its associated registration address as of September 2017. The vehicle attribute table from Oregon DEQ provided the year, make, model, vehicle type, fuel type, and combined city/highway fuel economy of all registered Portland metro vehicles based on VIN.

As the focus of this analysis is on fuel use by personal-use vehicles, special effort was made to eliminate commercial vehicles from the dataset. Registration addresses were spatially joined to parcel-level land use data contained in Metro's RLIS taxlot shapefile. Homes with an unusual number or composition of vehicles (e.g. multiple vehicles of the same type, especially work trucks and vans) were closely scrutinized. Apparent personal-use vehicles registered to businesses were also excluded because without a home address, it was unclear to what location vehicle use should be attributed.

\section{$\underline{\text { VMT Calculations }}$}

Next, annual vehicle mileage was estimated from the vehicle odometer readings by annualizing the difference between the two most recent readings taken since 2013. We considered as valid readings that were at least one year apart and non-negative. It must be noted that testing in the Portland metro region is only required for vehicles model year 1975 and newer, so 16,130 older vehicles are not included in this dataset (7). Additionally, DEQ does not require testing on vehicles less than three years old, so the most recent vehicle model year with known VMT in our dataset was 2014 (7). Electric vehicles are also omitted from the DEQ odometer reading dataset, as they do not directly emit any greenhouse gasses, and are not tested by the state of Oregon. Valid VMT readings were established for 556,952 vehicles within the analysis area (52\% of those registered).

\section{Figure 1: Flowchart of Existing Conditions Methods}

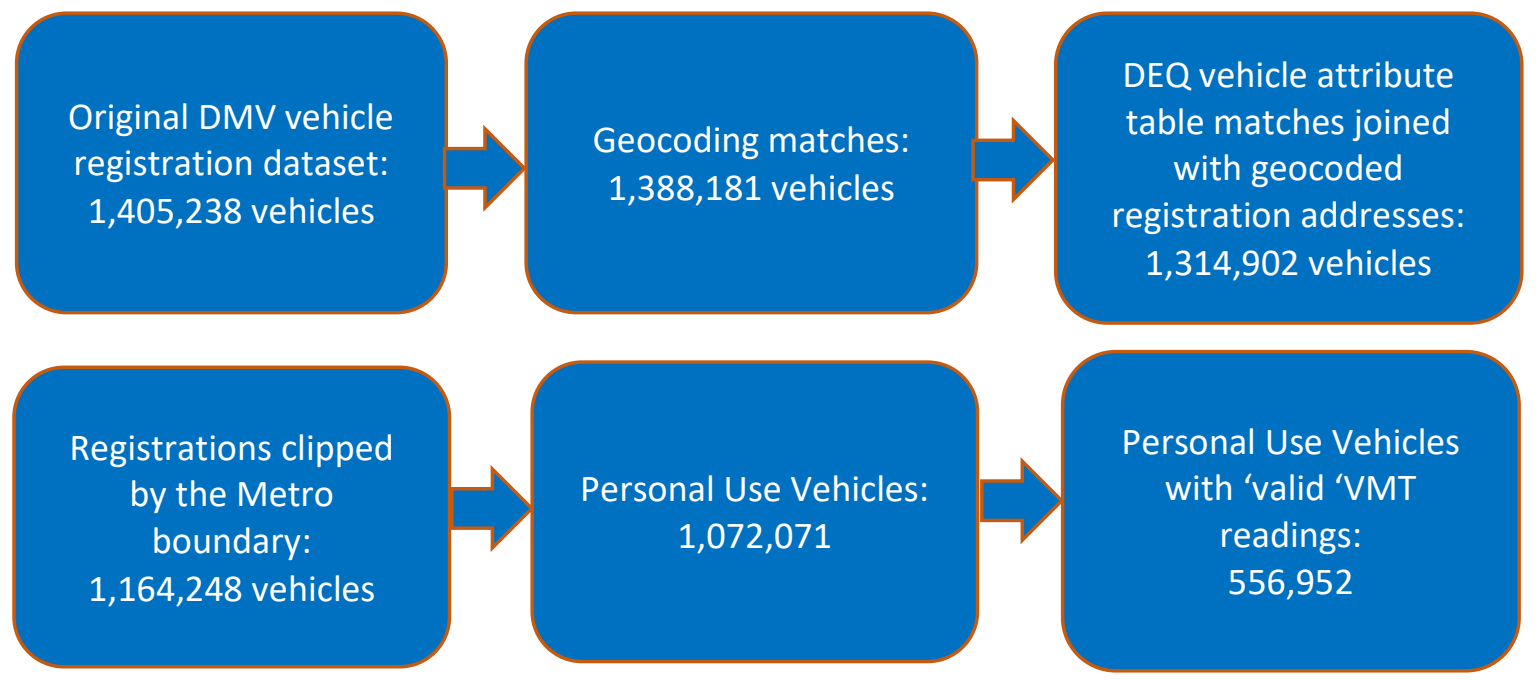




\section{Equity Determination}

To make observations about vehicle attributes and usage patterns through an equity lens, data were aggregated to the block group-level and joined to ACS sociodemographic statistics such as race and median household income. Next, we created a scoring system for block groups so that we could draw a distinction and make comparisons between disadvantaged communities and the metro region as a whole. Our "Equity Score” system follows the guidelines laid out by PBOT's "Equity Matrix," which divides block group median household income into quintiles and then assigns each block group a score of 1 through 5, with 1 being the highest-income earners, and 5 being the lowest (9). The same is done for the percent of people that identify as something other than white, with 1 being the lowest, and 5 the highest (9). These two scores are added together, and each block group is assigned a score of 2 through 10 (9). We followed the same formula, but applied it to all of Metro, not just the city of Portland. Block groups with a score of 8 or higher were defined as "communities of concern."

\section{FINDINGS}

\section{Vehicle Attributes: Vehicle Age}

As seen in Figure 2 below, while the age of vehicles registered in communities of concern skew slightly older, there is minimal difference in the frequency distribution of vehicle model years between communities of concern and the population generally both within Portland, and Metrowide.

Figure 2: Vehicle Model Year Frequency Distribution: All Vehicles vs. Communities of Concern

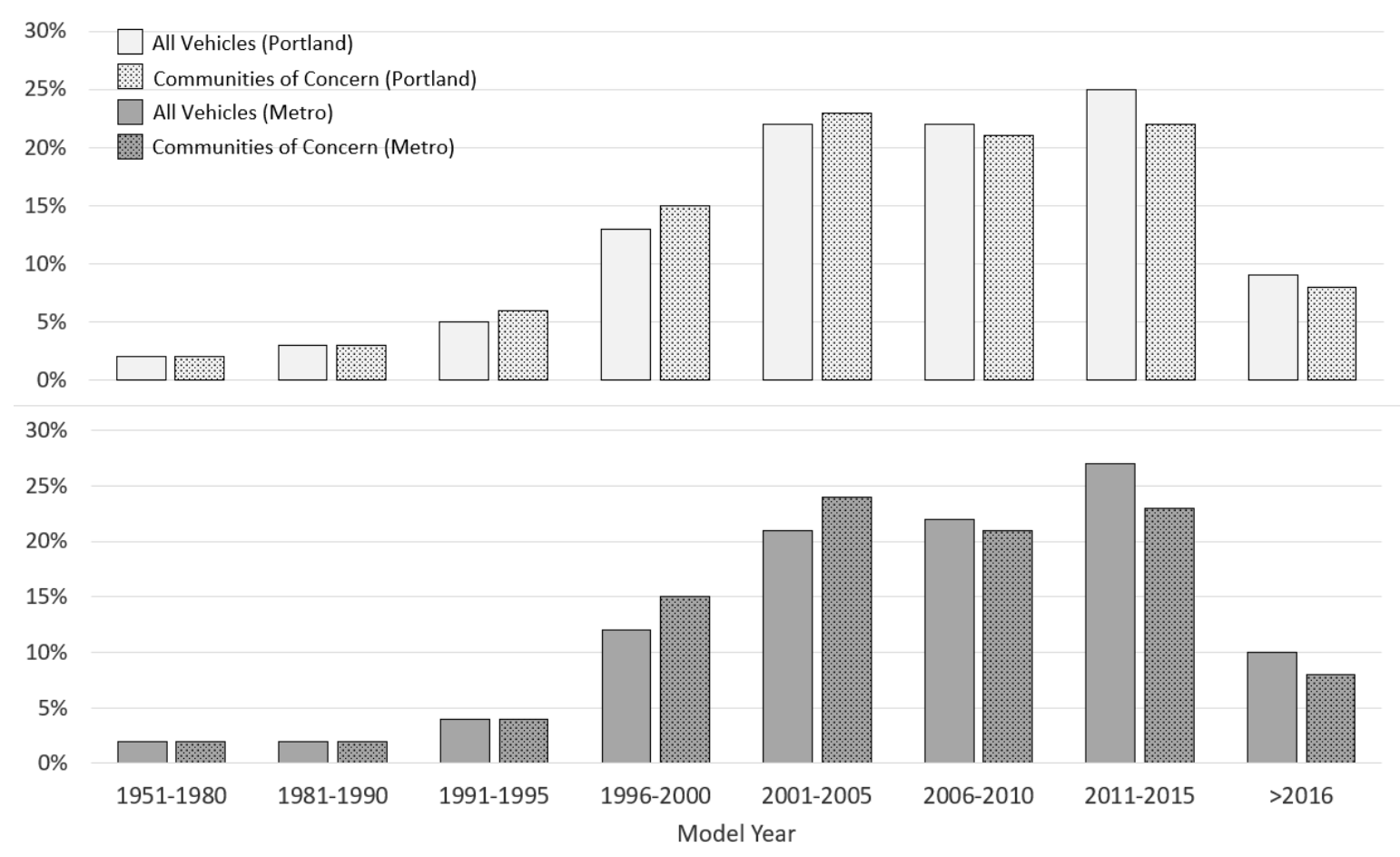


Visual inspection of the spatial distribution of older vehicles indicates a higher concentration of vehicle built prior to or in the year 2000 on the east side of Portland (Figure 3).

Figure 3: Distribution of Vehicles Age (Model 2000 and older)

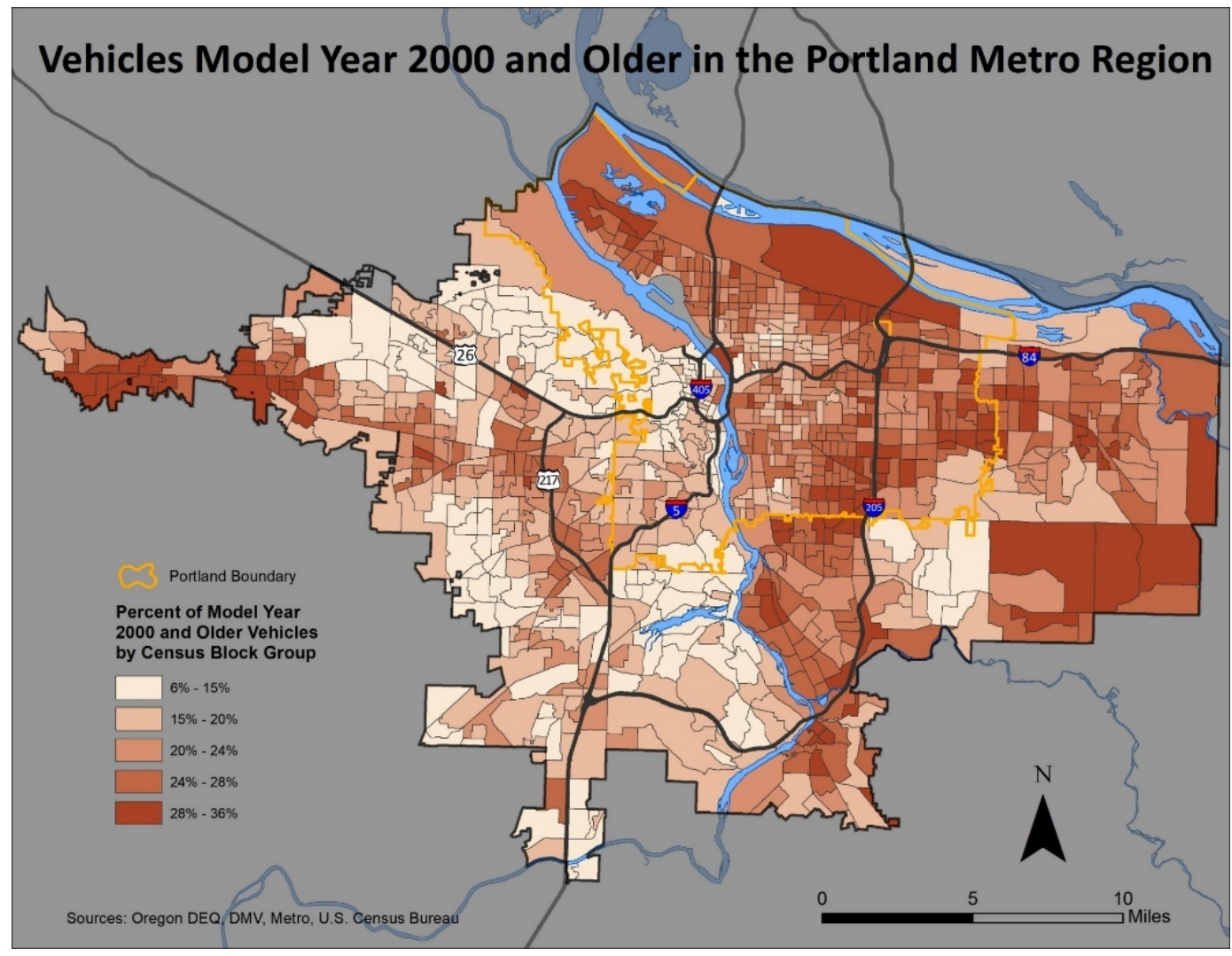

\section{Vehicle Attributes: Fuel Economy}

Average miles per gallon (MPG) differs little among equity score groups. All block groups with an equity score under 10 have an average MPG greater than the national average for all personal vehicles in Metropolitan Statistical Areas (MSAs) of 22.8 (NHTS/EPA data, authors' calculations). The average fuel economy of vehicles in block groups with an equity score of 10 , the lowest-income and highest percent of non-white identified, is less than one-tenth of a mile per gallon under the national average, and within one MPG of the lowest equity score areas (Figure 4). 
Figure 4: Average Miles per Gallon (MPG) by Equity Score

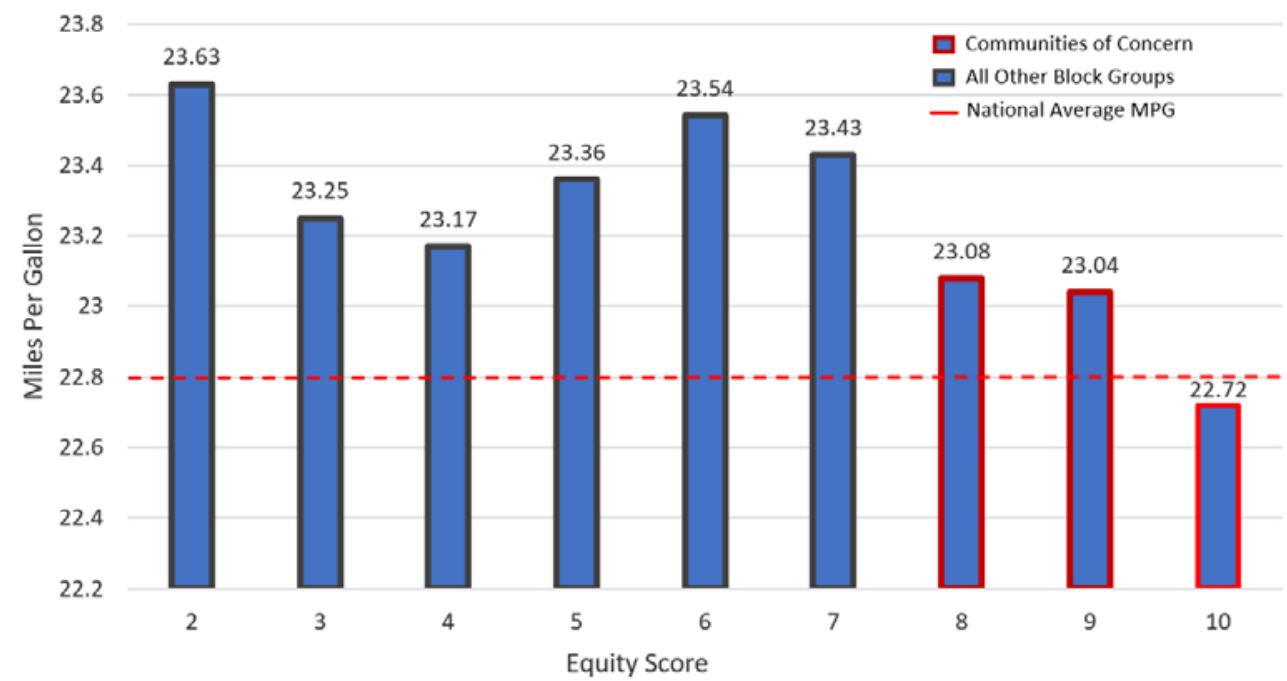

Spatially, average fuel economy is highest in block groups closest to the central city and tends to decrease radiating outward, particularly on the east side of the region (Figure 5).

Figure 5: Distribution of Fuel Economy of Passenger Vehicles

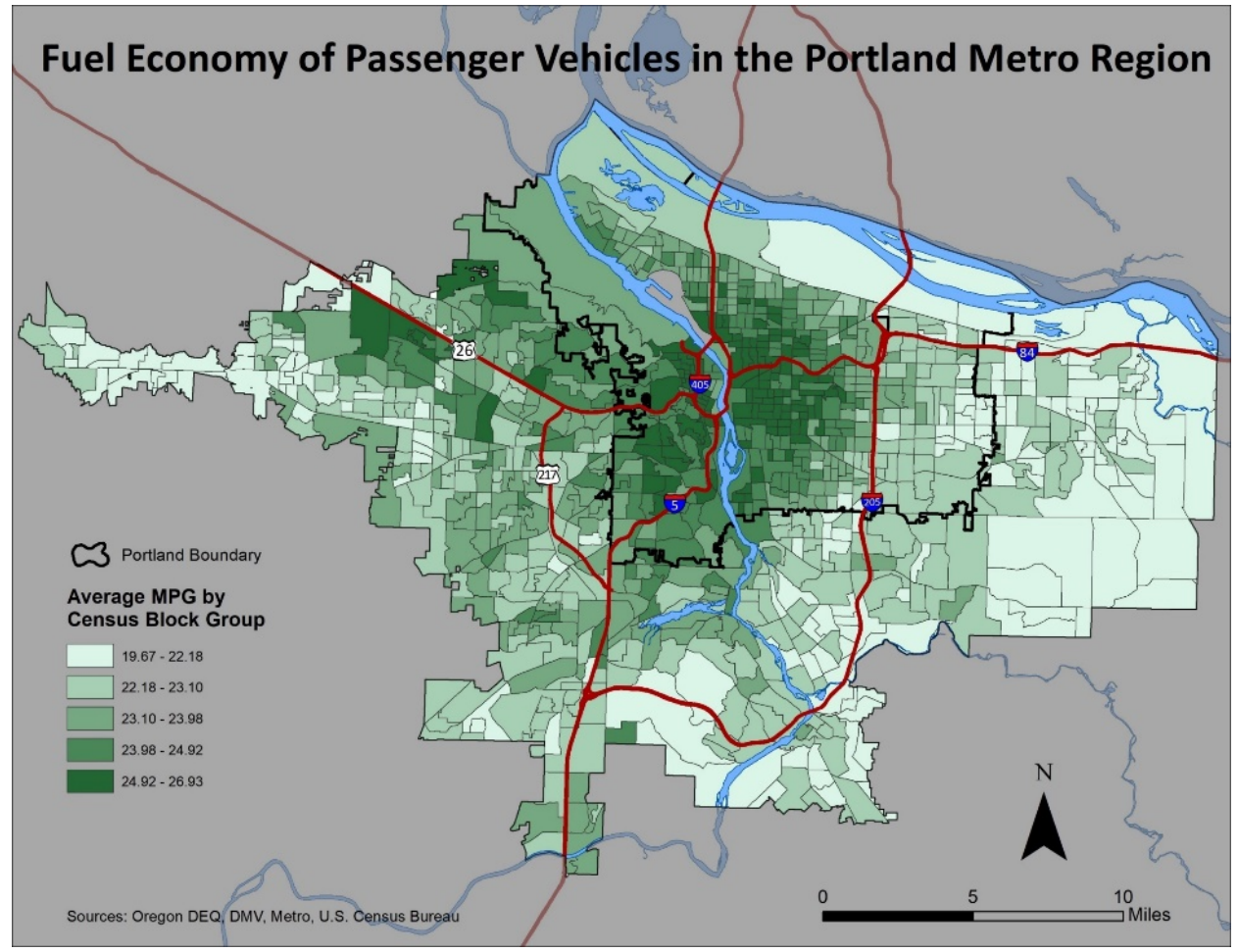

Figure 6 displays the percent of vehicles that are "gas-guzzlers” by equity score. In this analysis "gas-guzzlers" are defined as any vehicle achieving under 22.5 MPG combined, which is the minimum threshold for which the gas-guzzler tax is assessed on new vehicles by the Internal 
Revenue Service (IRS) (8). While the proportion of gas-guzzlers by equity score ranges only 4.5 percent between groups, some patterns emerge. The percentage of gas-guzzlers is greatest in high-income, mostly white areas, and decreases with income and the percentage of whiteidentified population before beginning to increase in the lowest-income and highest minority population areas. All equity score groups are below the national average (per NHTS/EPA) of $57.4 \%$ gas-guzzlers.

\section{Figure 6: Percent of Gas-Guzzlers by Equity Score}

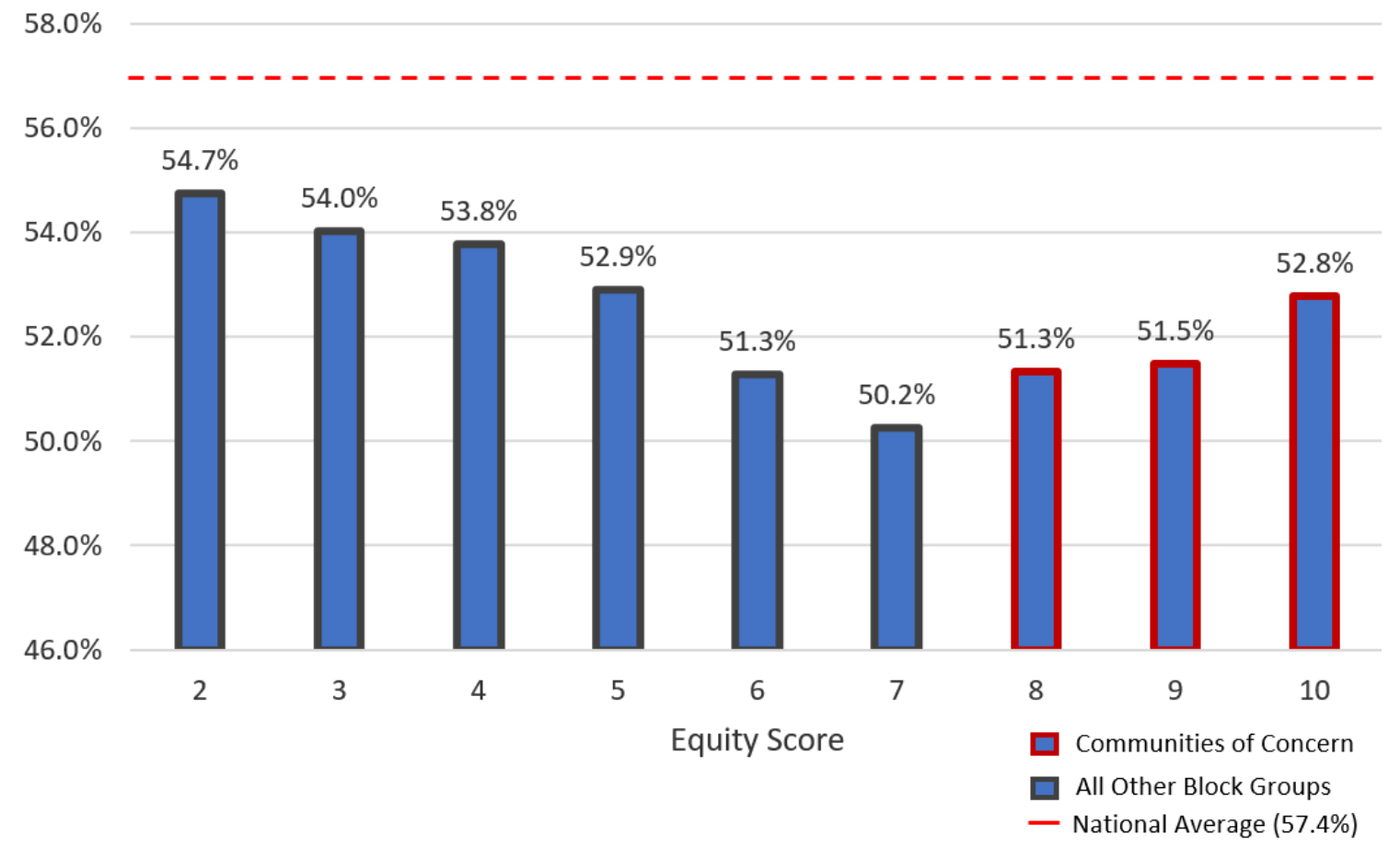

Gas-guzzlers skew slightly older than the general population of vehicles. The mean vehicle model year both Metro-wide and within the city of Portland is 2006, while the average model year for gas-guzzlers is 2004 in Portland, and 2005 for the entire Metro region. Figure 7 displays the most vehicle type among gas guzzlers by block group. Of note is the dominance of cars as a gas-guzzler vehicle type within the city of Portland, and the prevalence of sport utility vehicle (SUV) gas-guzzlers outside the city limits. If policy makers seek to encourage or incentivize the use of more efficient and/or alternative fuel vehicles, the physical attributes of the current vehicle fleet should be considered to accommodate the needs of a wide range of life-stages and family sizes. Presently, most fully-electric vehicles are sedan-sized or smaller. Larger families, or people that require a large cargo capacity may depend on an SUV or truck. Hybrids of these types could be a stopgap until more large electric vehicles come to market. Alternatively, the role of conventional internal combustion engine truck and SUV on-demand, short-term rentals may warrant consideration so that families could own a small electric vehicle for daily driving and rent a larger vehicle for occasions where it is required (i.e. moving day, long distance trip, errands). 
Figure 7: Distribution of Gas-Guzzlers by Dominant Vehicle Type

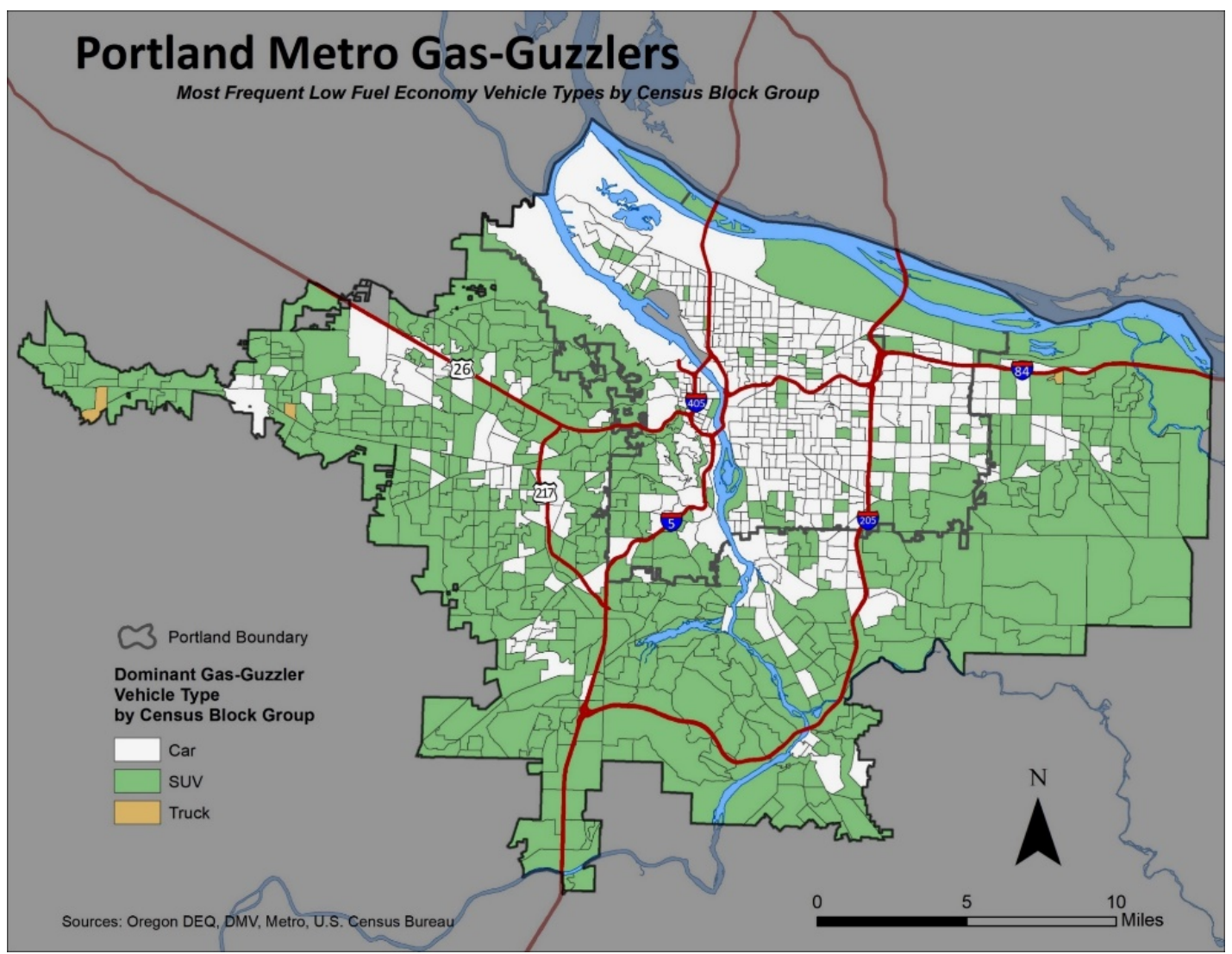

Vehicle Attributes: Hybrids and EVs

Figures 8 and 9 show the number of EVs and hybrids by equity score. The stark difference in the number of EVs and hybrids registered in communities of concern lends credence to the notion that high-income earners are able to 'buy in' to alternative fuel vehicles, while low-income communities have not yet been able to realize the gains in efficiency offered by hybrid and electric vehicles. 
Figure 8: Electric Vehicles by Equity Score

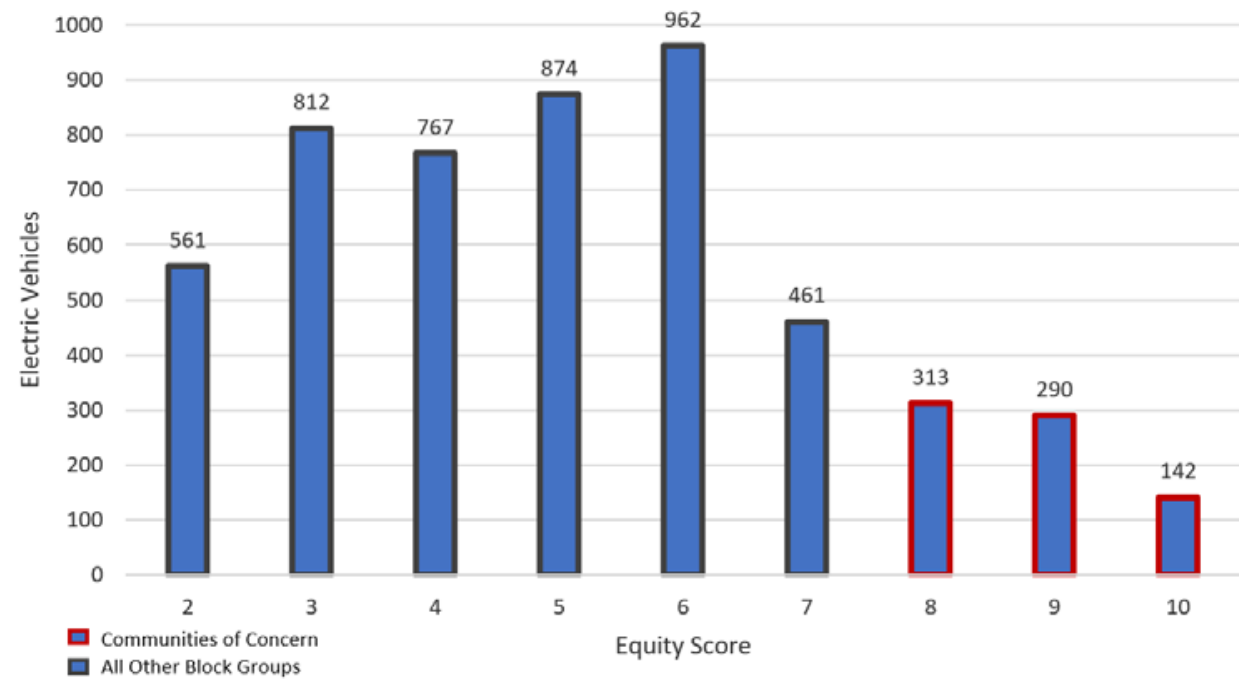

Figure 9: Hybrid Electric Vehicles by Equity Score

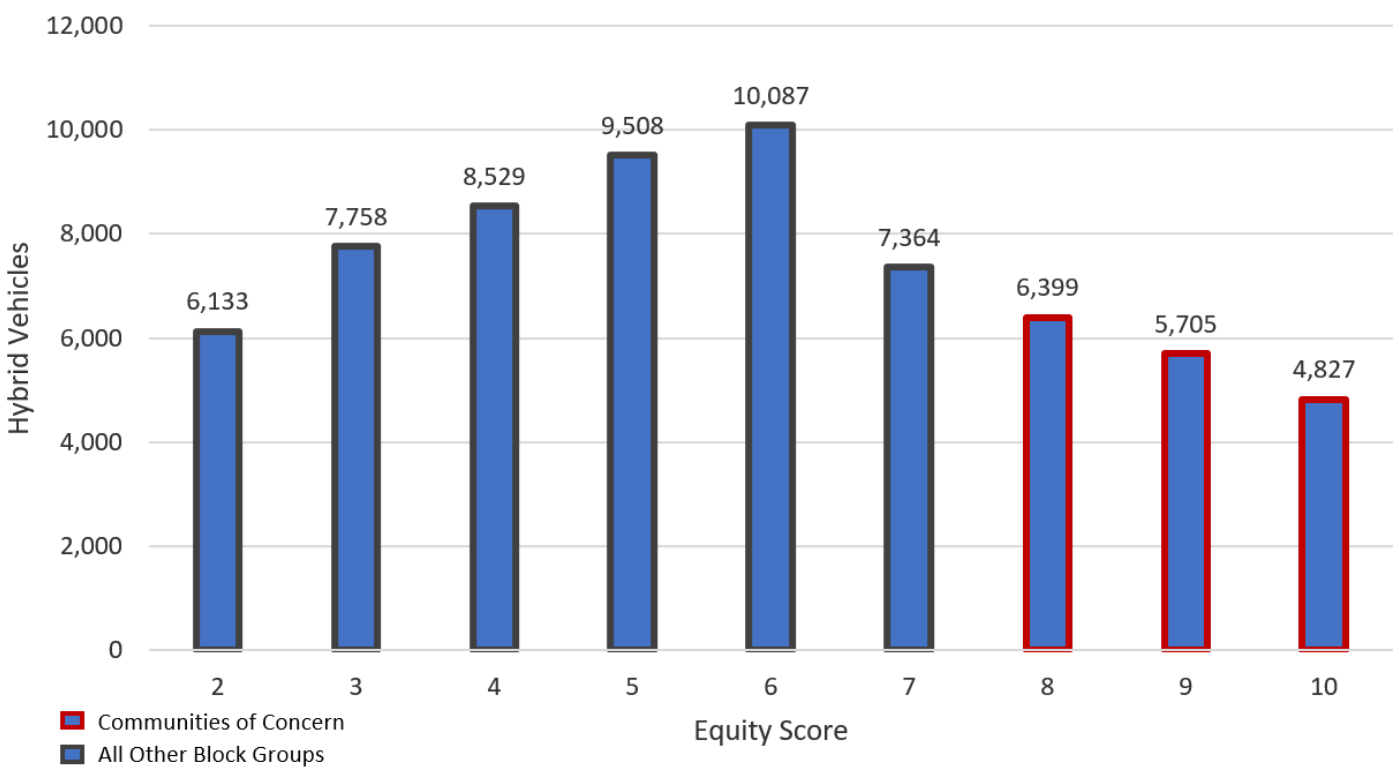

Spatially, we observed a higher concentration of hybrid vehicles within the city of Portland than on the extremities of the Metro region (Figure 10). Within Portland, there are more hybrids registered to addresses on the west side and inner-east side. Note the relative lack of hybrids registered east of Interstate 205. 


\section{Figure 10: Distribution of Hybrid Vehicles}

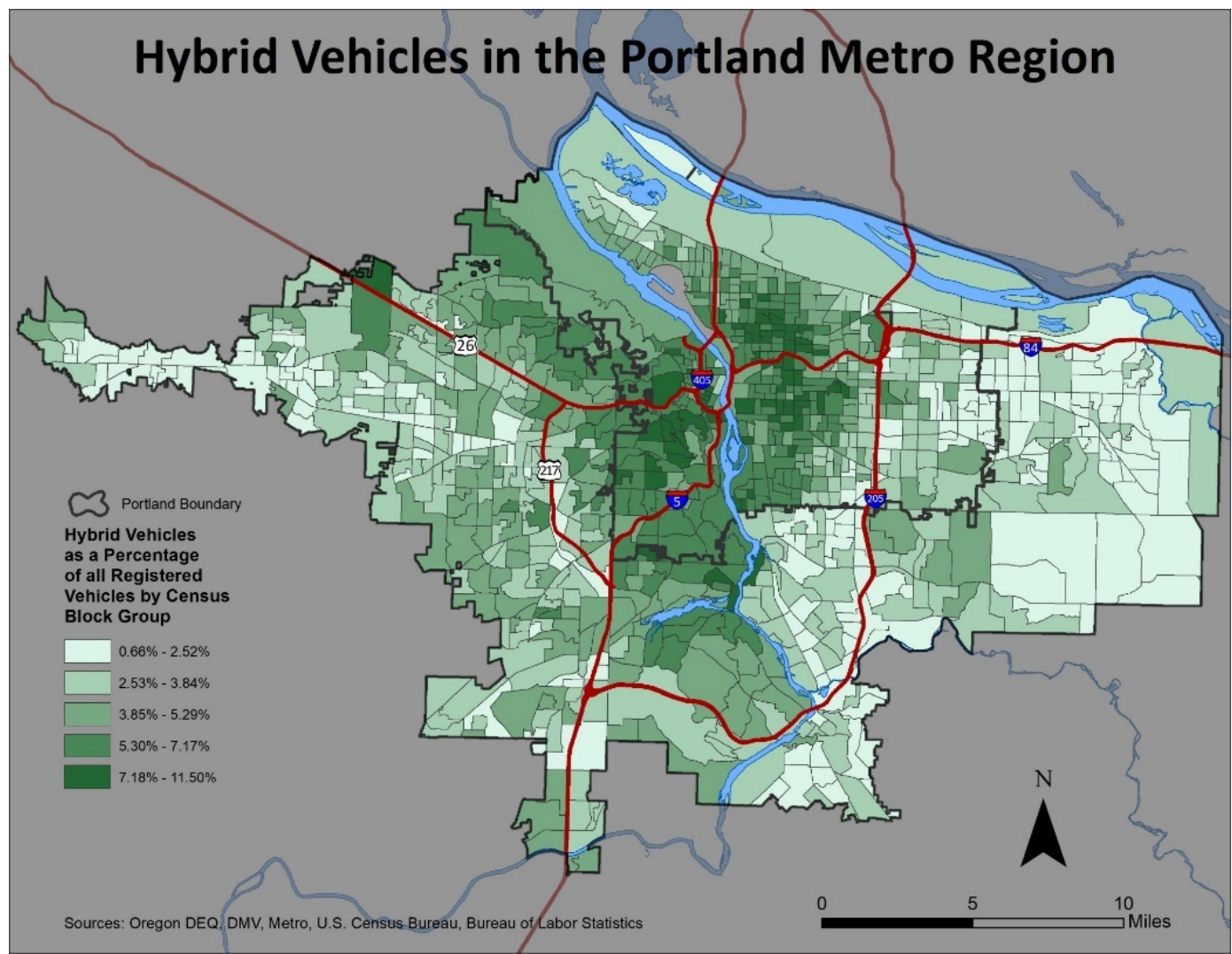

Currently, electric vehicles make up such a small percentage of cars registered in Portland that clear spatial patterns are difficult to discern. However, block groups that do have electric vehicles in any significant number tend to be located closer to the city center (Figure 11). This may be, in part, due to the limited range of electric vehicles at present, which renders them more practical for shorter, in-town trips. 
Figure 11: Distribution of Electric Vehicles

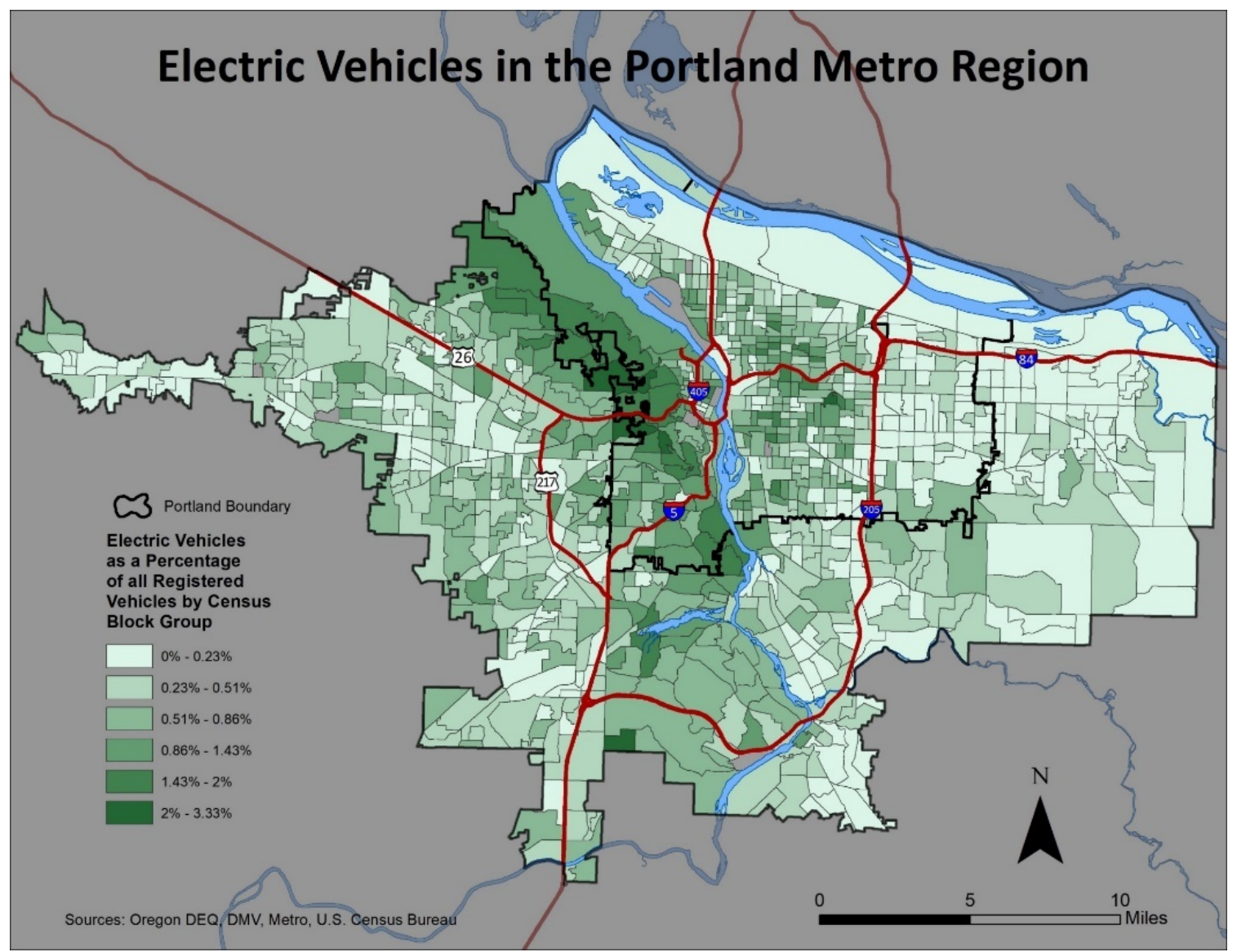

Vehicle Use: Vehicles Miles Travelled (VMT)

Region wide, the block group average vehicle VMT ranges from 5,743 to 10,423 miles annually. Block groups closest to the city center tend to be on the low-end of that range, while the highest average annual VMT is observed in block groups further away from the urban core (Figure 12). 
Figure 12: Distribution of Average VMT

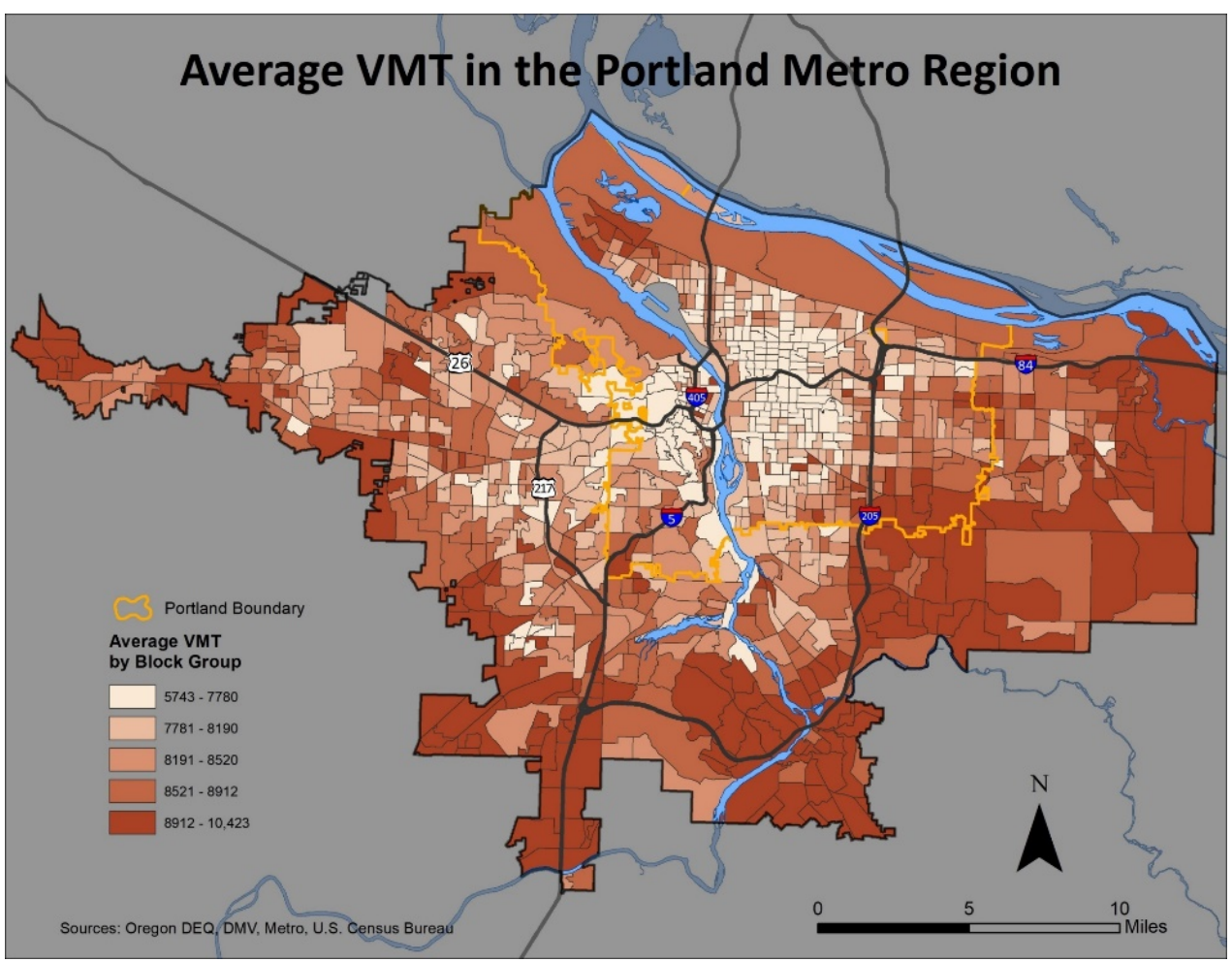

By equity score, there little differentiation in VMT (Figure 13). While it is worth noting that the least amount of annual miles is observed in the highest-income equity score group, 2 , and the most annual miles in the lowest-income equity score groups, 9 and 10, they are only separated by 222 annual vehicle miles. All groups are well below the national average (per NHTS) of 10,270 miles.

Figure 13: Average Annual VMT by Equity Score

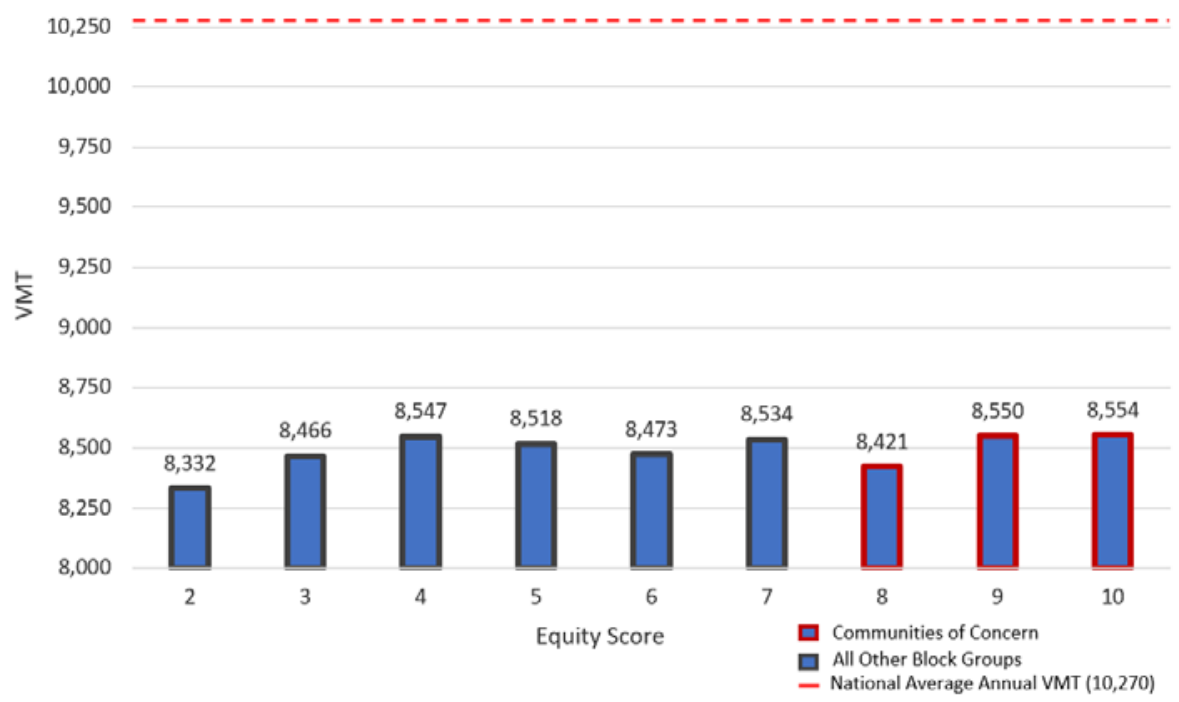


Metro-wide, average annual vehicle VMT is higher than it is within the city of Portland (Figure 14). Metro-wide and within the city of Portland, vehicles designated as gas-guzzlers average marginally fewer annual miles than the general population of vehicles, while vehicles registered in communities of concern average more annual miles.

Figure 14: Average Annual VMT Comparison Portland vs. Metro Region

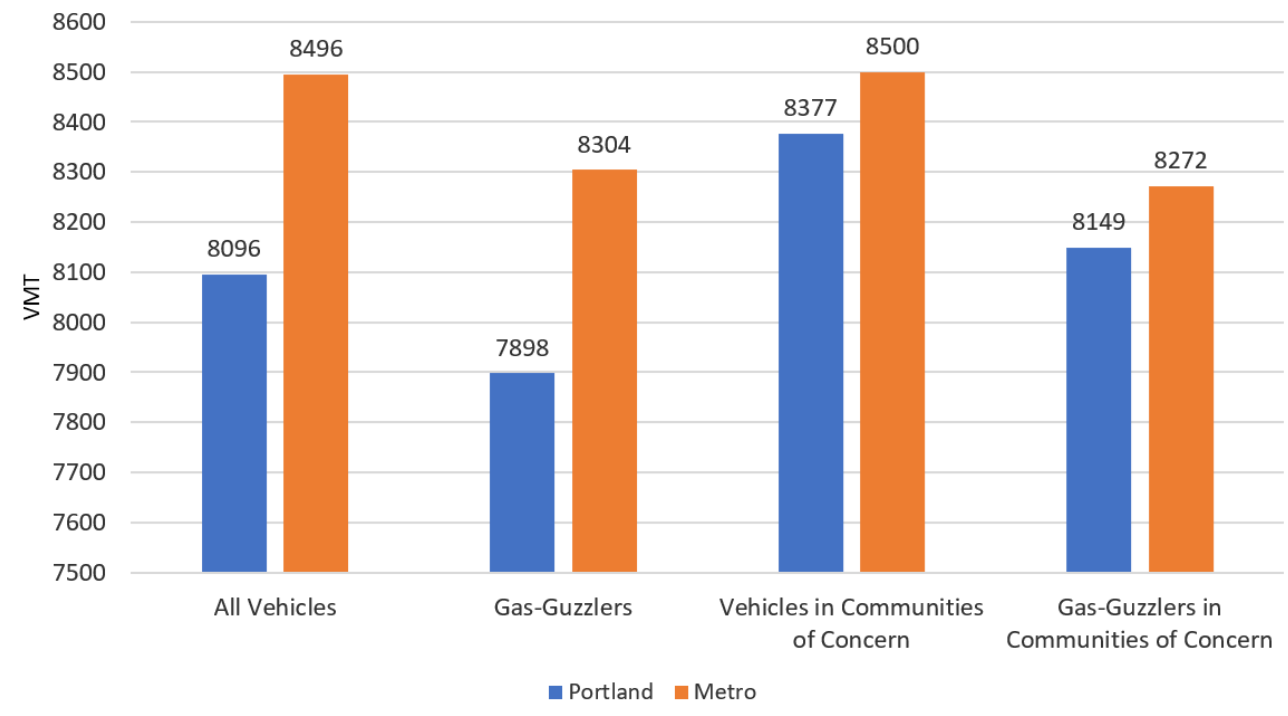

Vehicle Use: Fuel Consumption

The spatial patterns of fuel consumption in the Portland Metro region mirror those of VMT (Figure 15). Block group-level average annual fuel consumption increases radiating outward from the city center. 
Figure 15: Distribution of Annual Fuel Consumption

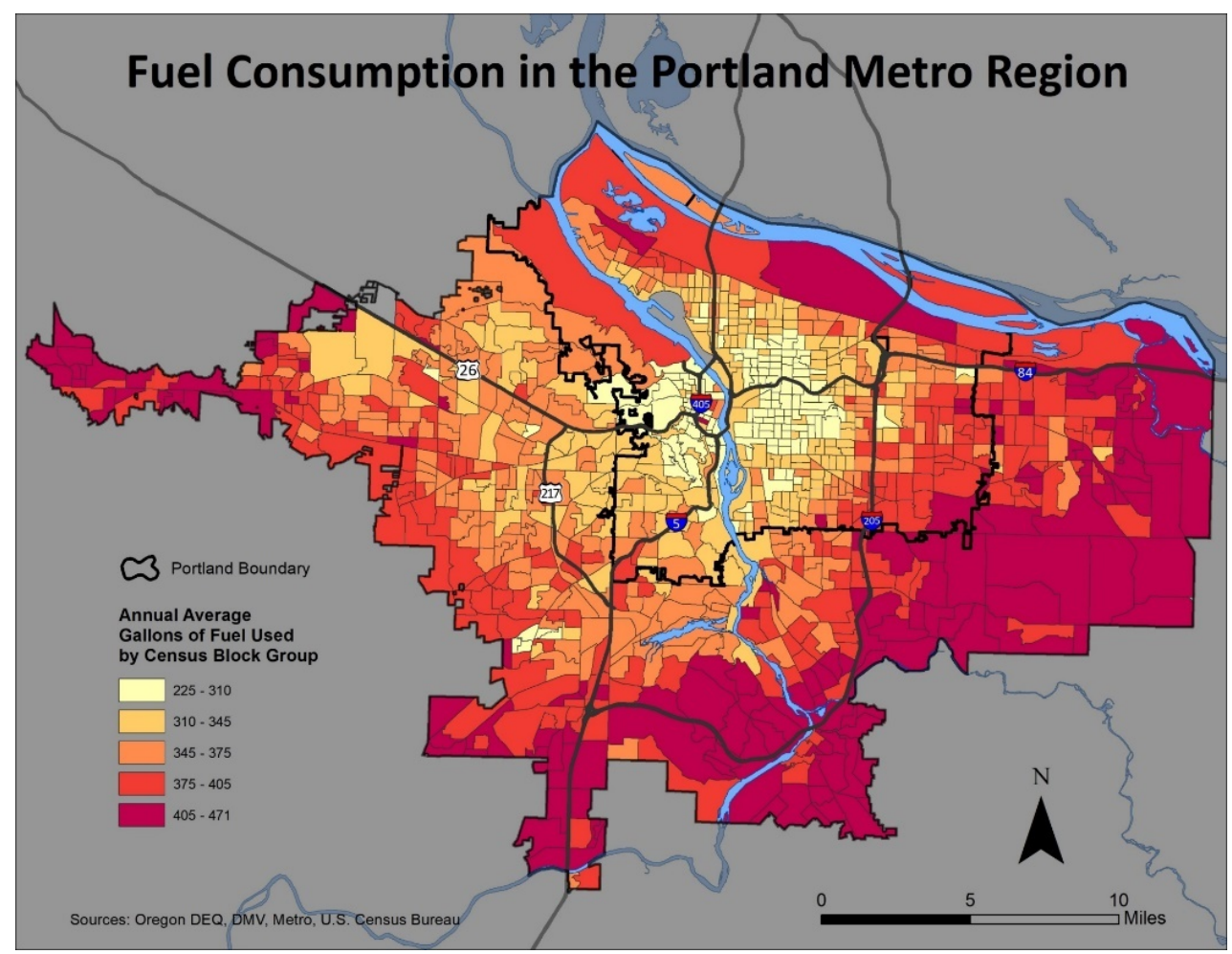

There is minimal difference in fuel consumption by equity score group, with a range of only 12 gallons, or about the size of the gas tank on an average sized car. All groups are well below the national average annual fuel consumption of 482 gallons (as calculated by the NHTS dataset).

\section{KEY TAKEAWAYS}

- There is not convincing evidence that vehicles registered to owners in lowerincome block groups consume more fuel, thus more $\mathrm{CO}_{2}$, than in higher-income block groups.

- EV ownership is concentrated in higher-income, mostly white block groups.

- The average vehicle travels fewer miles in Portland than in the rest of Metro, and both are well under the national average for metro areas.

- Policies should consider the needs that the physical attributes of people's current vehicles may fulfil, and how various interventions may or may not be effective in encouraging people to switch to alternative fuels. 


\section{VMT Model}

\section{RESEARCH APPROACH}

While the DMV and DEQ data sets provided vehicle characteristics and usage at the vehicle level, they could not be reliably connected to important household predictors of vehicle use, such as income, household composition, and number of vehicles owned, as block group-level sociodemographic data were the finest grain available at the time of the existing conditions analysis. Therefore, we chose to model VMT using the recently released 2017 National Household Travel Survey (NHTS) as the estimation set, as it includes income, vehicle year, make, model, and self-reported annual mileage at the vehicle/household level, as well as basic built environment information at block group level. The model also controlled for number of workers and children in the household, as well as regional differences. Given that, in addition to systematic effects, a range of idiosyncratic factors likely influences the annual miles a vehicle covers, the amount of variation explained by the model ( $12 \%)$ seemed reasonable, if lower than we might have hoped.

\section{FINDINGS}

\section{Vehicle Attributes: VMT by Fuel Type}

The model revealed that hybrids and diesel cars (and to a lesser extent diesel trucks) are driven more than expected, controlling for other factors, while plug-in hybrid electric vehicles (PHEV) and EVs are driven less by nearly a thousand miles per year. This likely reflects the unique characteristics of these vehicles at present. All four vehicle types typically have a low fuel cost per mile relative to gasoline internal combustion engines, but EVs are limited by range while hybrids and diesels are not.

Plug-in hybrids are not limited by range in the same way that EVs are, as their electric motors are augmented by traditional internal combustion engines once the initial charge that allows electric-only driving (typically under 50 miles) has been depleted. Beyond that initial batterypowered range, plug-ins act as traditional hybrid vehicles, which are less fuel-efficient than EVs. Therefore, it is most economical to operate plug-in hybrids for shorter trips so that they may be recharged before using gasoline reserves. This may explain why we observe a predicted decrease in annual VMT for PHEVs despite shared characteristics (decreased cost per mile and no range limitation) with diesels and traditional hybrids. Consumers keen to see a return on their initial investment (plug-ins carry a premium over traditional hybrids) utilize their vehicles in a manner that minimizes the per-mile cost.

\section{Vehicle Attributes: VMT by Vehicle Age}

As seen below in Figure 16, aside from some variation pre-1990 and in 2017, there is a nearlinear positive relationship between vehicle model year and average annual VMT. 
Figure 16: Average Vehicle VMT by Model Year (NHTS)

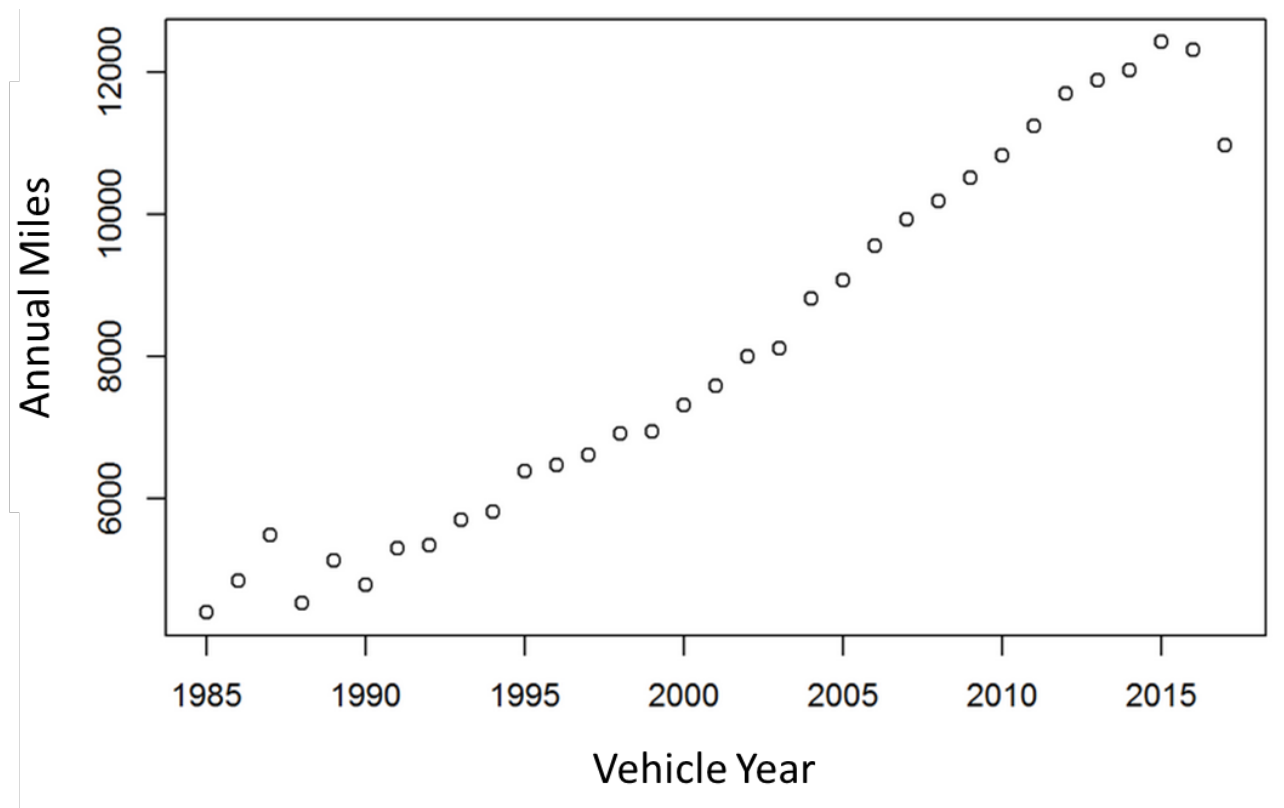

While newer cars tend to get driven more, they also achieve superior fuel economy than older vehicles regardless of fuel type. Since the 1975 enaction of CAFE standards, the average adjusted miles per gallon of new light-duty vehicles sold in the United States has increased from 13.1 miles per gallon to 24.2 miles per gallon as of model year 2014 (Figure 17) (10). 
Figure 17: Fuel Economy by Model Year (NHTS)

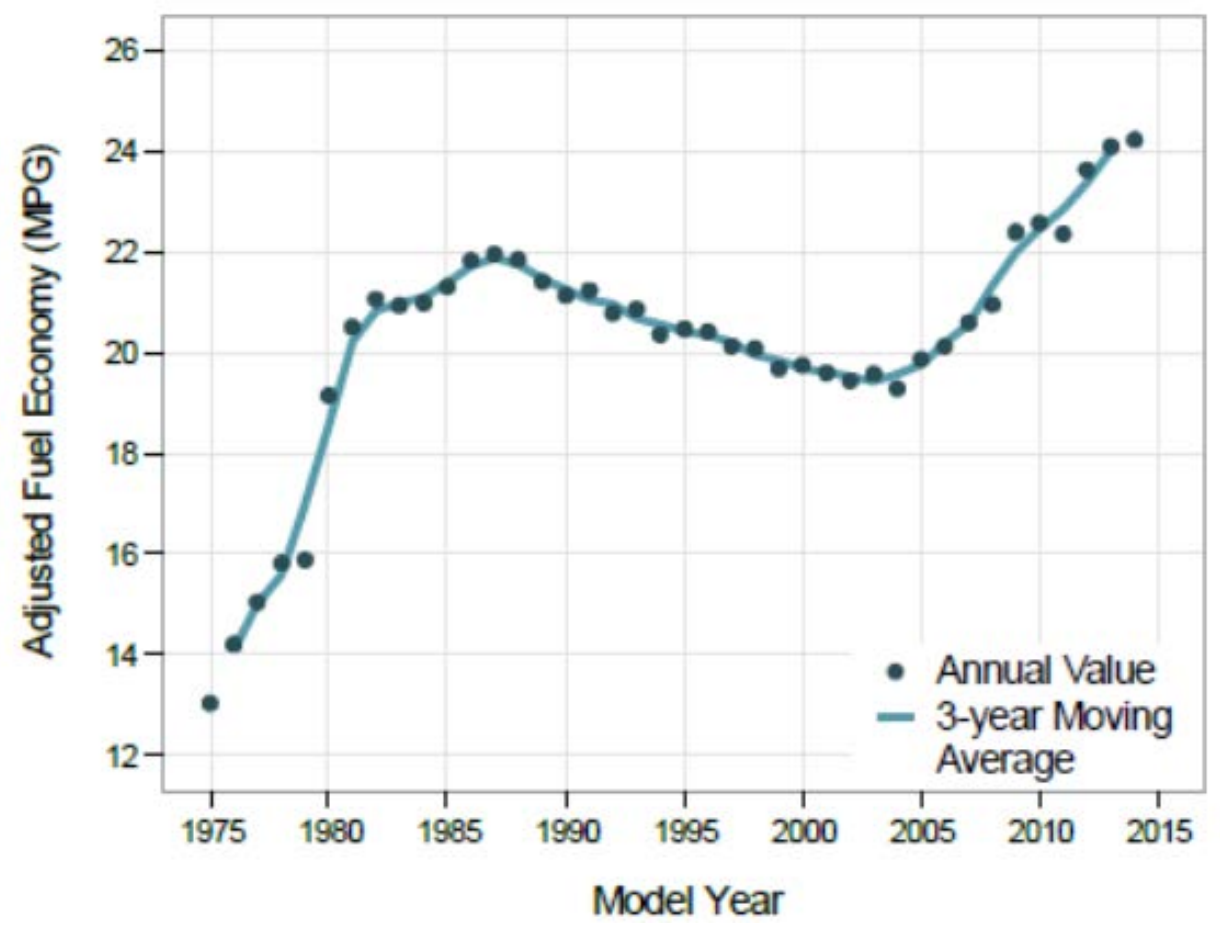

\section{Sociodemographics, Household Location, and VMT}

We found an interesting inter-relation among household income, residential location density, and how much a vehicle is driven. As expected, driving increases with income (Figure 18) and decreases with density. However, higher income groups reduce driving more in response to density than do those with lower incomes, partly or in some cases fully offsetting the direct income effect on vehicle miles. For example, all else equal, a vehicle in the highest income group ( $\$ 200 \mathrm{~K} /$ year or more) would be expected to cover 4,470 more miles per year than the same vehicle in a lower-income household. In a moderately dense urban location (5,000 people/mi ${ }^{2}$ ), though, the high-income household would be expected to drive the vehicle about the same amount as the low-income household. This might reflect the increased ability of higherincome households to cash in on "density bonuses" by shopping at neighborhood (but likely more expensive) stores, living closer to work, or by making use of alternate transportation options. 
Figure 18: Average vehicle VMT by Income (NHTS)

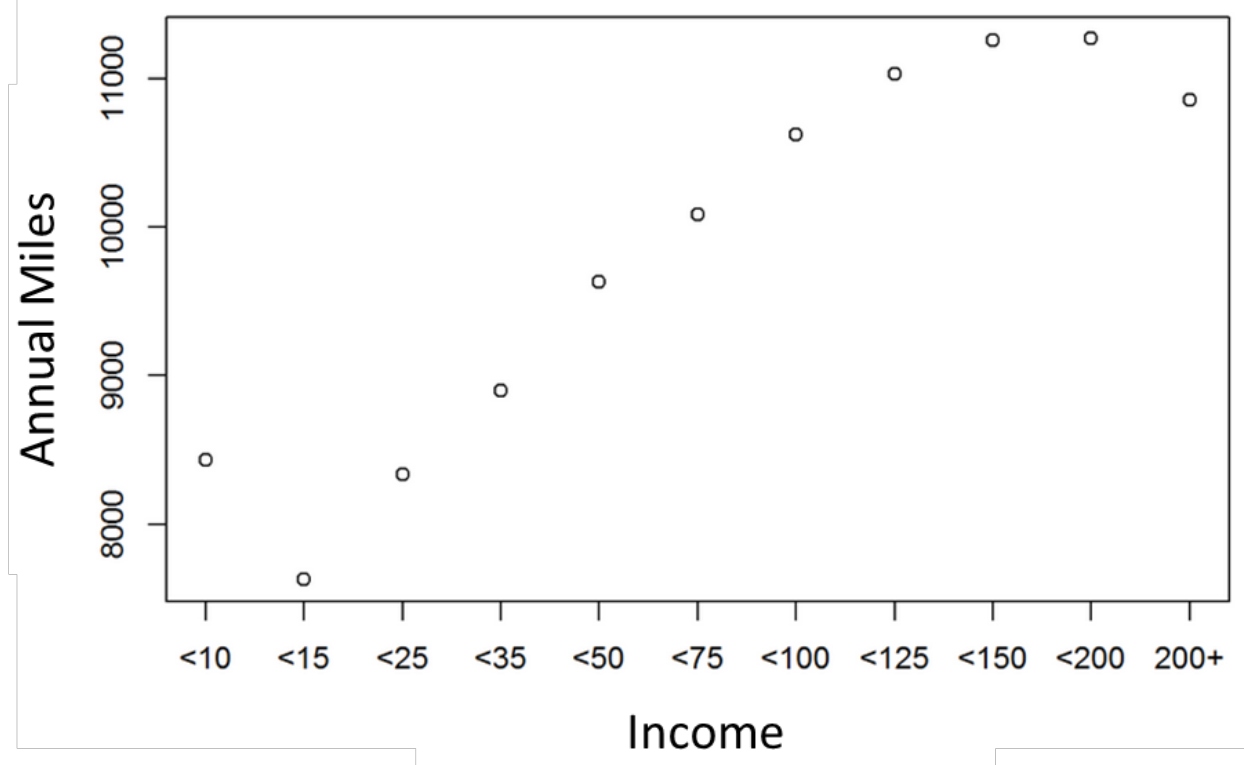

\section{Household Income and Vehicle Age}

Given the relatively high cost of even the base model of new vehicles, it no surprise that average vehicle age tends to decrease as household income increases. As seen in Figure 19, the mean vehicle age for the lowest income earners is around 12 years old, while households in the highest income bracket own vehicles that are just 7 years old on average. 
Figure 19: Average Vehicle Age by Income (NHTS)

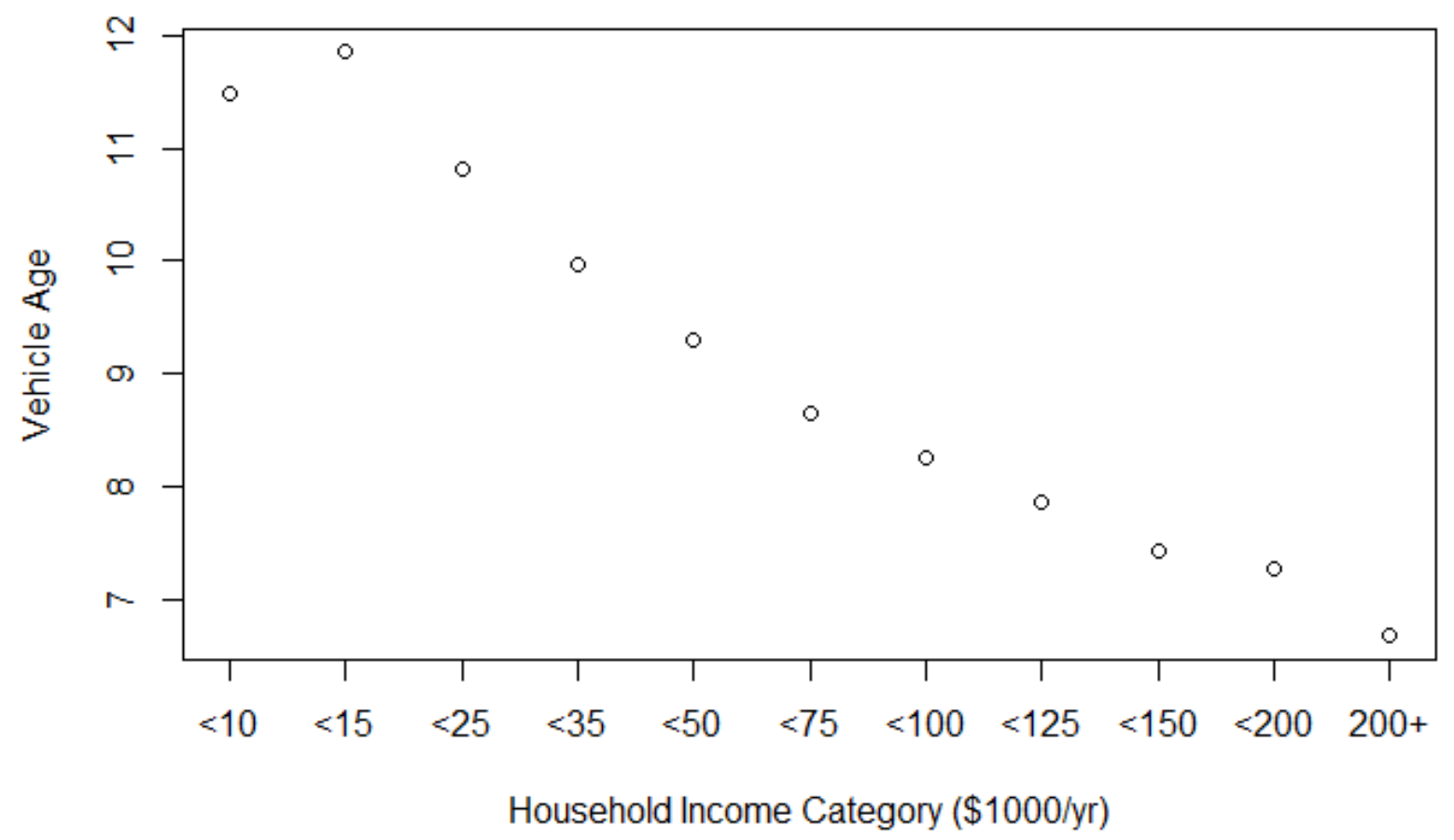

\section{Household Income and Fuel Economy}

As the model has revealed that high income earners tend to own newer vehicles, and EPA records show that personal-use vehicles have steadily improved their fuel efficiency over the past decade, it follows that wealthier households tend to drive vehicles that achieve superior fuel economy than low-income households (Figure 20). Average MPG increases gradually up until a household income of $\$ 200,000$ is reached, before increasing dramatically for those earning over $\$ 200,000$ annually.

Examining only conventional gasoline vehicles changes the picture (Figure 20). Fuel economy is practically identical across income groups, if not declining among households earning $\$ 200,000$ or greater, suggesting that high income groups "buy in" to efficiency via alternative fuel vehicles (EV, PHEV, or diesel cars/light trucks). Figures 8, 9, and 21 support this interpretation, showing a steady increase in the share of alternative fuel vehicles owned as household incomes rise from $\$ 25,000$ to $\$ 200,000$ annually. The highest income households earning over $\$ 200,000$ per year have by far the largest share at around $13 \%$ (vs. about a $2 \%$ share among low-income households). 
Figure 20: Average MPG by Vehicle Type and Household Income (NHTS)

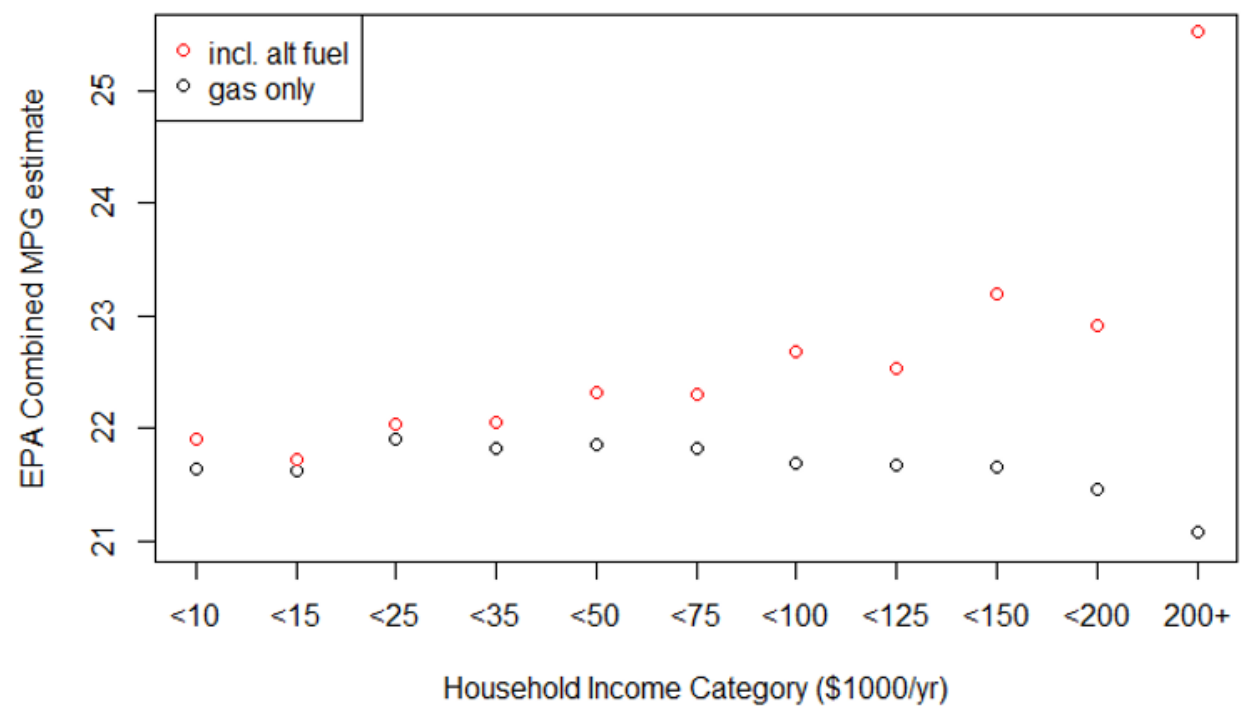

Figure 21: Share of Alternative Fuel Vehicles (including diesel) by Income (NHTS)

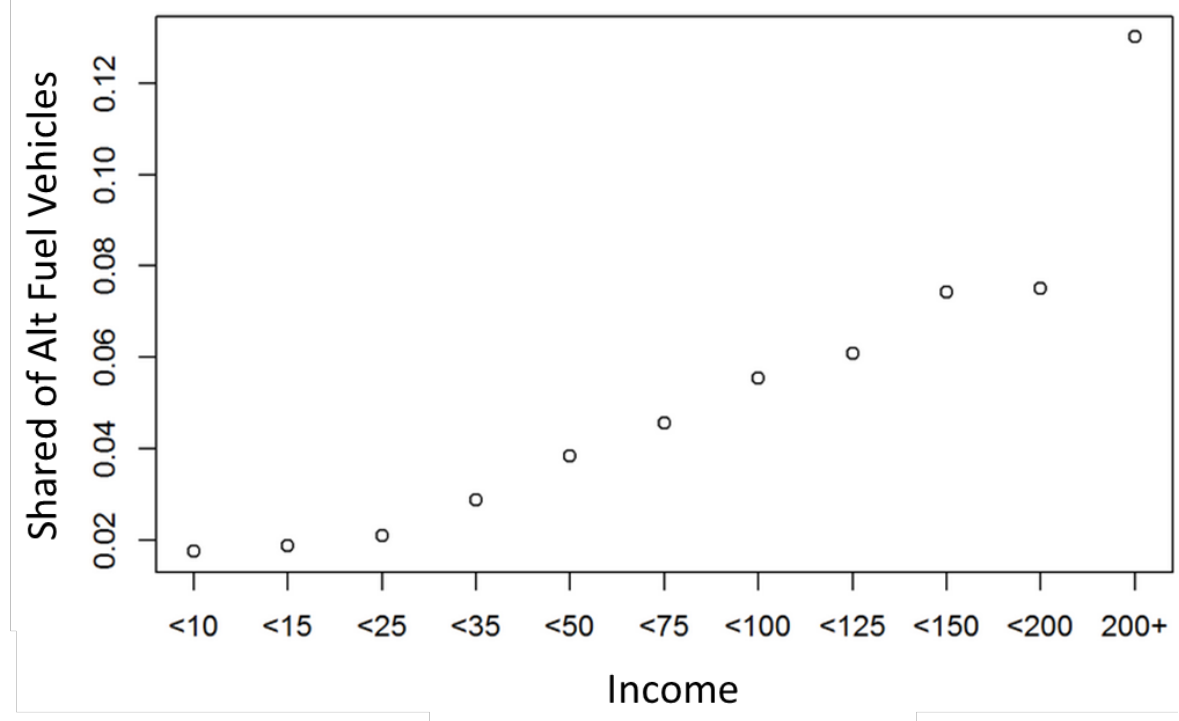




\section{Policy Scenarios}

Meeting ambitious carbon reduction targets like Portland's will clearly require a range of policies. We developed a model to explore potential for fuel savings through replacing a portion of the current personal vehicle fleet with new hybrids and EVs. While such technological substitution will not be enough on its own, given existing development patterns many of the current miles will continue to be driven in the near to medium term, and shifting those miles to more efficient cars and trucks will likely be part of many cities' strategies. We also consider urban densification as both an alternative and complementary policy to alternate fuel vehicles. Note that here density works (via the NHTS-based vehicle use model) only to curtail use of existing vehicles. Not able to be considered in this paper are potential reductions in vehicle ownership attributable to density.

The data clearly support the notion that alternative fuel vehicle efficiency benefits have to date been primarily accruing to wealthier households (Figure 8, Figure 9, Figure 19, Figure 20). Portland recognizes that, for a variety of reasons, policies will need to become more inclusionary to be effective in the long-run. We consider how shifting policy targets toward specific equity populations (lower-income areas) might affect both primary outcomes and the distribution of fuel saving and mobility benefits.

\section{METHODS}

We considered three primary policy scenarios designed around fleet shift toward alternate fuels, each with three different targeting methods (region-wide with and without an equity focus, and area average-based). In the equity area focused scenarios, we assumed a region-wide search for vehicles ("worst" $20 \%$ in each case) but with a bias toward lower (median) income areas. In those cases, we replaced vehicles in the starting in the poorest block groups until half of the $20 \%$ were replaced. In addition, we considered two place-based scenarios with only equity or density targets. Table 1 presents the proposed vehicle-centric and place-based scenarios and targeting mechanisms (See Appendix D for details on policy scenario assumptions). 


\section{Table 1: Policy Scenarios Used for Model}

Vehicle-centric Scenarios:

\section{Target Vehicles}

Clunker: Replace $1 / 2$ of oldest $20 \%$ of fleet with EV or PHEV.

Gas-guzzler: Replace $1 / 2$ of least fuel efficient $20 \%$ of fleet with EV or PHEV.

High VMT: Replace $1 / 2$ of vehicles with the highest $20 \%$ of VMT with EV or PHEV.

\section{Target Areas}

Region-wide: Target all vehicles within Metro.

Equity Focus: Bias towards lowest median household income block groups. *

Area Average Target: Target block groups where the fleet average efficiency is lowest, VMT is highest, or age is oldest.

* Vehicles were replaced starting in the lowest-income block groups until $1 / 2$ of the $20 \%$ were replaced

\section{Place-based Scenarios:}

\section{Scenario}

Equity Only: Replace $10 \%$ of the region vehicle fleet, focusing only on lowest income block groups.

Density Only: No fleet replacement; densify region by $10-20 \%$

\section{POLICY SCENARIO OUTCOMES}

The estimated impact of the policies considered, most of which involved replacing $10 \%$ of the personal vehicle fleet, ranged from detrimental (increased fuel use) to a maximum $12.8 \%$ regionwide fuel savings (Figure 22). The high end of that range would contribute almost a third of Portland's goal of a 41\% reduction in transportation-related carbon by 2030-a consequential policy outcome to be sure (2). Given the considerable efficiency advantage of EVs and their diminished rebound effect—at least at present—it is perhaps no surprise that they produced policy effects in all scenarios at least three times those of HEVs. The most effective HEV scenario resulted in only a $4 \%$ regional fuel savings (Figure 22). 
Figure 22: Fuel Savings Region-Wide: Hybrid vs. EV Replacement

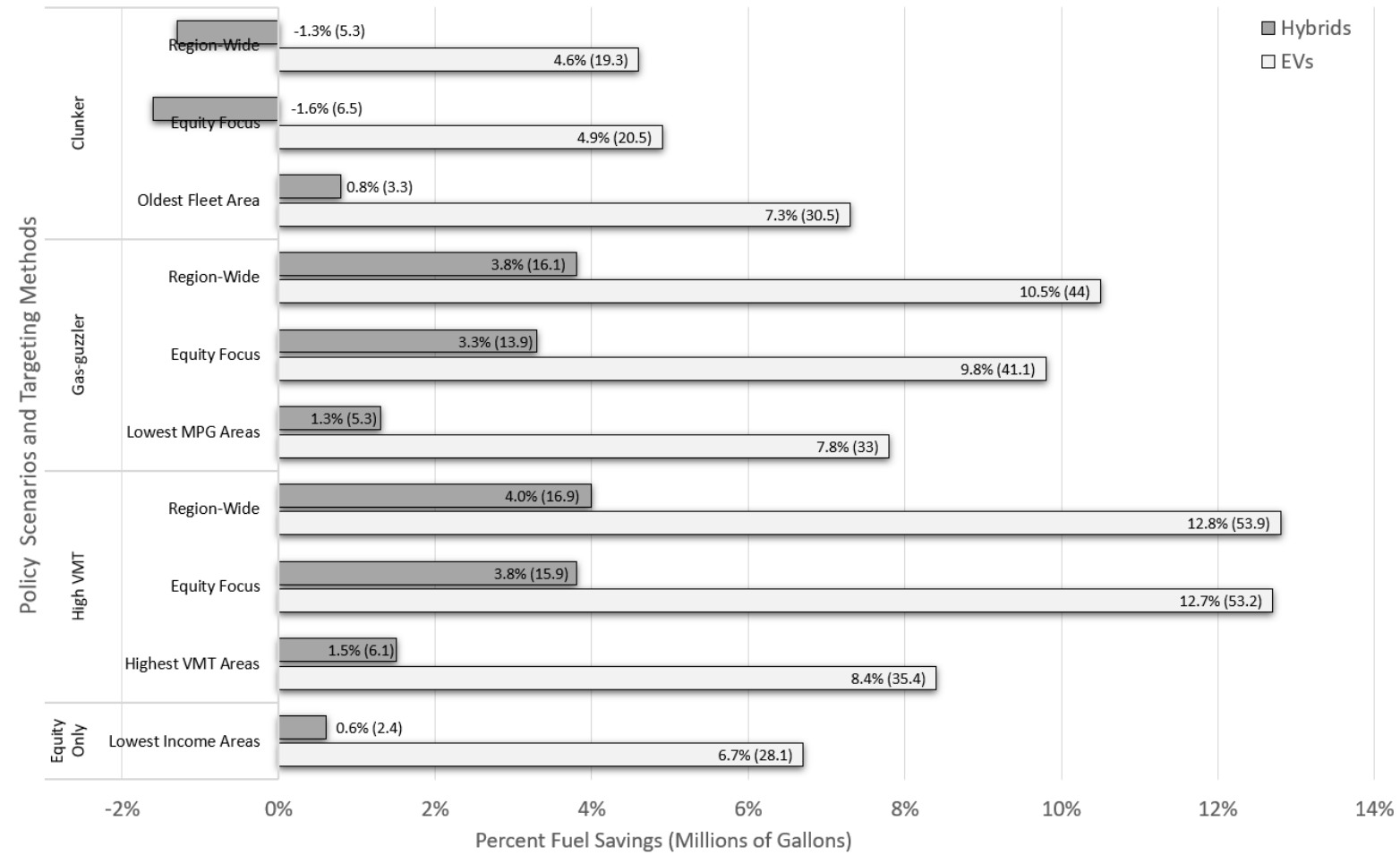

As for targeting strategies, where possible, identifying high use vehicles appears to be the most effective strategy, followed by identifying low efficiency vehicles (Figure 22). Targeting older vehicles proved to be an inferior option, partly because those are subject to the largest rebound effect and partly because older does not necessarily mean less efficient; in fact, geographic investigations showed considerable pockets of older but fuel efficient (likely smaller) vehicles in neighborhoods near the central city. In terms of geographic focus, targeting the "worst" vehicles by each criteria region-wide worked considerably better with the exception of targeting older vehicles (Figure 22). Area targeting might still be preferred, however, in cases where identifying or marketing to individual vehicles proved infeasible or where specific policies lend themselves more to an area by area approach; e.g., public EV charging infrastructure or outreach via local groups or events.

An encouraging finding was the performance of equity-biased policy scenarios. The "lowincome area first” strategy nearly equaled the results of the equity-blind region-wide targeting, suggesting the efficiency cost of equity consideration does not have to be high (Figure 23). Even the equity only strategy without specific vehicle targets provided about fifty percent of the bestperforming option's fuel saving in the EV scenario (Figure 23). There are certainly limitations in assuming benefits to lower-income areas will accrue proportionately to lower-income households. On the other hand, there are likely localized benefits even to households that do not participate in such programs (or do not own a vehicle at all), such as reduced air pollution and infrastructure supportive of vehicle sharing programs. 
Figure 23: Proportion of Region-Wide Fuel Savings Accrues to Lowest 20 Percent Income Areas

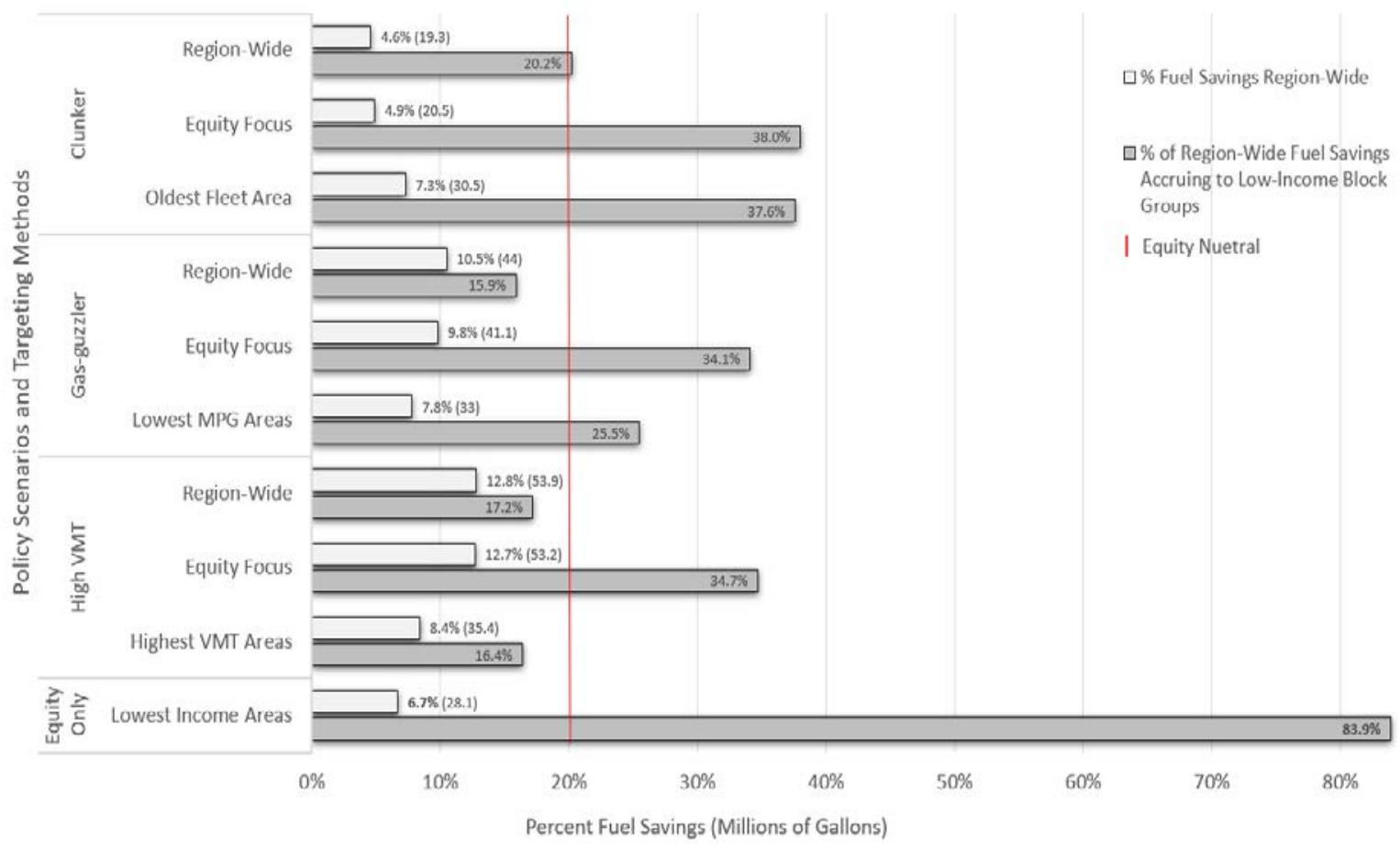

Figure 24 provides an equity accounting of mobility improvements by strategy focus and targeting methods. While increased VMT due to a newer vehicle or HEV presents a problem for reduced fuel consumption, for households facing a mobility deficit the so-called "rebound effect" might be viewed as a positive. Compared to the modest difference in fuel saving outcomes for the equity-biased options relative to region-wide focus (light gray bars), the differences in benefit captured by low-income areas (dark gray bars) are several times greater, generally about doubling the share of fuel savings and mobility increases going to the lowest quintile neighborhoods (Figure 23 and Figure 24). This is also a case where area targets for older (clunker) or low-efficiency vehicles (gas-guzzler) outperform region-wide targeting, likely because concentrations of older, inefficient vehicles coincide with poorer neighborhoods. It is worth noting that two of the highest efficiency scenarios (region-wide targeting of gas guzzlers and high VMT vehicles) are equity negative, with less than a fair share of benefits going to lower-income areas. This is highlights the potential that some policies may not achieve intended equity outcomes. Additionally, the equity potential of hybrids appears to be roughly on par with EVs in all scenarios, at least as measured here. There may be room for hybrids to be included in the policy mix when equity - and in particular increased access by personal vehicles - is a priority, or where purchase cost differences might favor hybrids (Figure 24). 
Figure 24: Mobility Increase to Lowest 20 Percent Income Areas

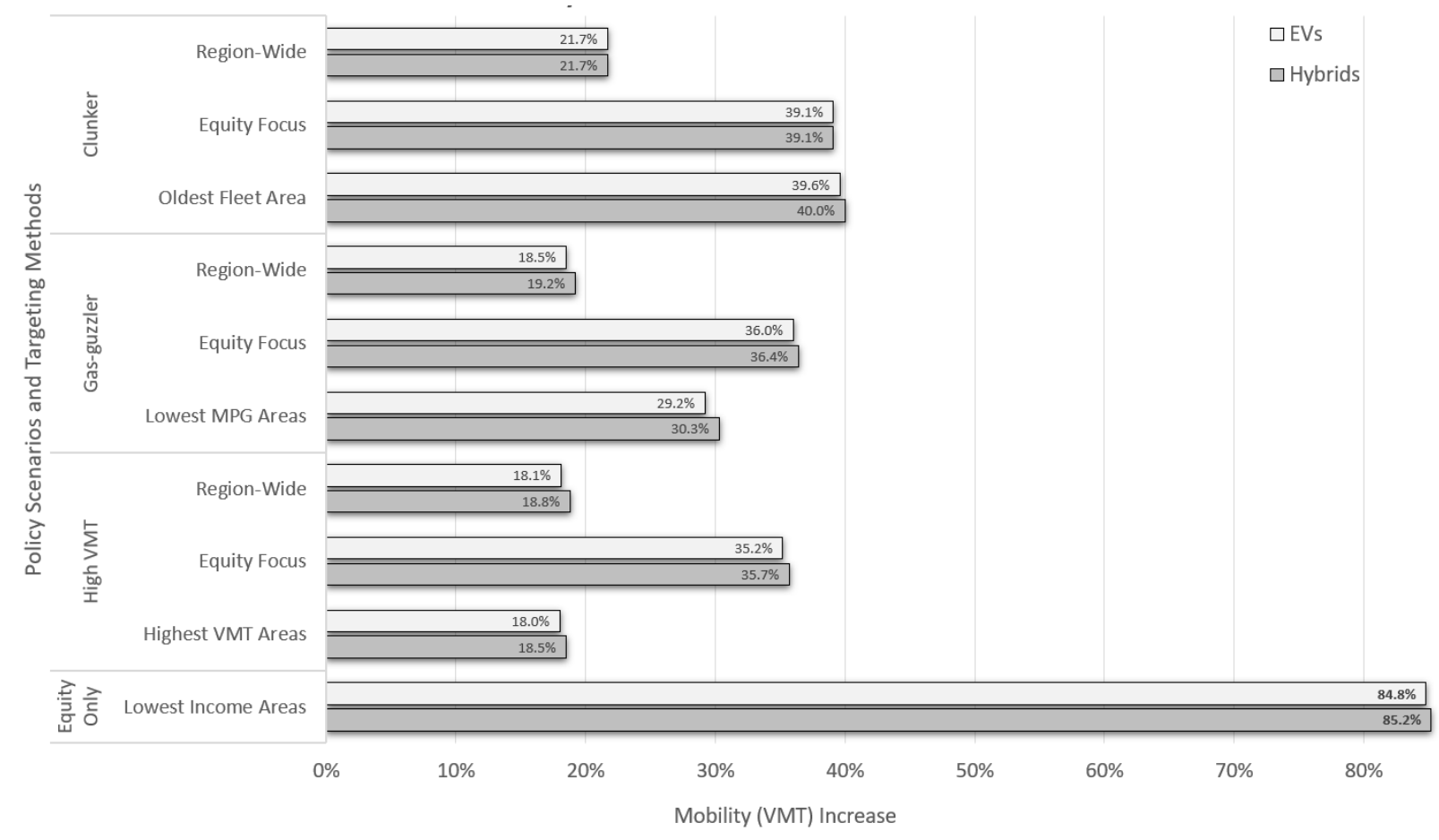

Finally, a density-only policy was considered, based on the VMT model findings that density reduces expected vehicle use, especially as income increases. Region-wide density gains of 10$20 \%$ contribute modest fuel savings of $0.5-1 \%$ of the regional total when considering only the impact on VMT by the existing fleet. Density gains could of course be more substantial than observed in the past, and they might contribute to reducing driving via other means, such as reductions in car ownership to approach the gains. It does not need to be either/or with vehicle technology and density; indeed, increasing density along with shifts to alternative fuel vehicles could mitigate the rebound effect, further reducing fuel use.

\section{COSTS/BENEFITS}

The societal benefit of fuel savings can be valued in terms of the social costs (such as negative impacts on agriculture yields, human health, and property damage from flooding worsened by climate change) saved from emissions abated. Schindell (2015) estimated the social cost of atmospheric release from one gallon of gasoline burned at $\$ 3.80$ (11). The social cost of the onegallon equivalent of coal generated-electricity is $\$ 8.06$, and $\$ 2.83$ for natural gas generatedelectricity (12). Given Portland's current energy mix of $44 \%$ coal, $24 \%$ natural gas, and 32\% non-fossil fuel, we estimated the average savings in social costs in Portland to be $\$ 3.80$ for 
hybrids (the entire social cost of one gallon), and $\$ 3.37$ per gallon for electric vehicles (accounting for the higher social cost of coal power) (13). Under the best performing policy scenario in which 10 percent of high VMT vehicles are replaced region-wide, the estimated average social cost savings per vehicle replaced would be $\$ 639$ per year for hybrids and $\$ 1,804$ per year for electric vehicles, including expected "rebound effects" on vehicle mileage. Therefore, vehicle replacement subsidies of up to $\$ 1,804$ per electric vehicle per year could be justified. Additionally, the social benefits of electric vehicles in the form of emissions abatement could increase over time as electricity generation becomes cleaner, which is a likely outcome considering Multnomah County's commitment to 100\% renewable energy by 2050 (14).

\section{KEY TAKEAWAYS}

- Low income households tend to drive older vehicles, but they are not driven as much as the vehicles of high income earners.

- The vehicles driven by low-income households are no less efficient than those driven by high income households when excluding alternative fuel vehicles.

- Higher income households make up a large proportion of alternative fuel vehicle owners.

- Results vary considerably depending on how vehicle replacement are should be targeted:

- Targeting high use and low efficiency vehicles is more effective than targeting old vehicles, due in large part to rebound effects.

- Individual vehicle targeting is more effective than area-based targeting.

- Equity-based scenarios successfully re-directed fuel savings and mobility benefits to low-income areas.

- Subsidies of up to $\$ 1,803 /$ year for replacement of high VMT vehicles with EVs could be justified in Portland by reductions in social costs of air emissions.

- Hybrids may be a necessary stopgap until electric vehicle prices decrease, range is extended, and a wider variety of vehicle types is available. 


\section{References}

1. Global Climate Change Vital Signs of the Planet. Causes. National Aeronautics and Space Administration. https://climate.nasa.gov/causes/. Accessed July 31, 2018.

2. Climate Action Plan. City of Portland and Multnomah County. June 2015. https://www.portlandoregon.gov/bps/article/531984. Accessed July 31, 2018.

3. State of the Air 2018. American Lung Association. Compare Your Air Tool. http://www.lung.org/our-initiatives/healthy-air/sota/city-rankings/compare-your-air.html. Accessed July 30, 2018.

4. “Oregon Cities Receive Mixed Grades for Air Quality.” American Lung Association. April 18, 2018. http://www.lung.org/local-content/_content-items/about-us/media/pressreleases/oregon-cities-receive-mixed.html. Accessed July 30, 2018.

5. A snapshot of the greenhouse gas inventory for the Portland metropolitan region. Metro. Spring 2010. https://www.oregonmetro.gov/sites/default/files/2015/05/29/10116_climate_change_fact sheet_pla_csc.pdf. Accessed July 31, 2018.

6. MacArthur, J., Harpool, M., \& Scheppke. Survey of Oregon Electric Vehicle \& Hybrid Owners. TREC-RR-1259. Transportation Research and Education Center (TREC) Portland State University. July 2018. https://trec.pdx.edu/research/project/1259/Survey_of_Oregon_Electric_Vehicle_\&_Hybri d_Owners

7. Oregon Driver \& Motor Vehicle Services. Oregon.gov. https://www.oregon.gov/ODOT/DMV/Pages/index.aspx. Accessed July 7, 2018.

8. Equity Matrix. Portland Bureau of Transportation. https://www.portlandoregon.gov/transportation/74236. Accessed March 30, 2018.

9. Tax form 6197 - Gas Guzzler Tax. Internal Revenue Service. October 2005. https://www.irs.gov/pub/irs-pdf/f6197.pdf. Accessed Sept 10, 2018.

10. Saulsbury, B., Hopson, J.L., Greene, D.L., \& Gibson, R. (2015). Status and Issues for Consumer Fuel Economy in the United States. U.S. Department of Energy.

11. Shindell, D. T. (2015). The social cost of atmospheric release. Climatic Change, 130(2), 313-326.

12. Fuel Comparison Chart. Energy.gov. October 29, 2014. https://www.afdc.energy.gov/fuels/fuel_comparison_chart.pdf. Accessed September 3, 2018.

13. Portland Plan Background Report - Energy. 2009. http://www.portlandonline.com/portlandplan/index.cfm?a=270874\&c=51427. Accessed September 3, 2018.

14. 100\% Renewable Energy Resolution. June 1, 2017. https://multco.us/multnomah-county-renewable-energy-resolution-6117-amended. Accessed September 10, 2018. 


\section{Appendix A: DMV and DEQ data limitations}

- While the DMV and DEQ data sets provided vehicle characteristics and usage at the vehicle level, they could not be reliably connected to important household predictors of vehicle use, such as income, household composition, and number of vehicles owned, as block group-level sociodemographic data were the finest grain available at the time of the existing conditions analysis. Therefore, vehicle registrations were aggregated to the block group level in order to make assumptions about the vehicle owners. This method cannot capture sociodemographic variation within each block group.

- The split of mileage between multiple vehicles within one household is unknown.

- The assumption must be made that the vehicle owner resides at the registration address, and that the vehicle has remained with one owner during the period of VMT estimation.

- Temporal discontinuity in the VMT estimates: VMT was estimated by annualizing the two most recent DEQ emissions tests that were at least 9 and $1 / 2$ months apart in order to simulate 4 seasons of driving. Tests are required every two years, but may be repeated as often as necessary until a vehicle passes emissions. The window used to estimate VMT for ranges from 2013 to 2017.

- We do not have VMT readings for electric vehicles and vehicles less than three years old as they are exempt from DEQ inspection. 


\section{Appendix B - Transferability of NHTS data to Portland Context}

To ensure that a national sample of MSA's would reasonable transfer to Portland's specific characteristics, we compared the block group-level average annual VMT from known odometer readings of our DMV and DEQ datasets with the predicted VMT of our NHTS-based model. As seen in the below figure, the majority of block groups fell within plus or minus 1,000 miles, on average, or the same as the precision of our DEQ-supplied odometer readings. The distribution of estimated high and low VMT areas also matched reasonably well with the odometer data. There was only a slight upward bias in the NHTS-based model at the block group level (240 $\mathrm{mi} / \mathrm{yr}$ ). These results left us confident that the model results could be usefully applied to our Portland policy context.

\section{Block group average vehicle miles, model versus odometer estimates}

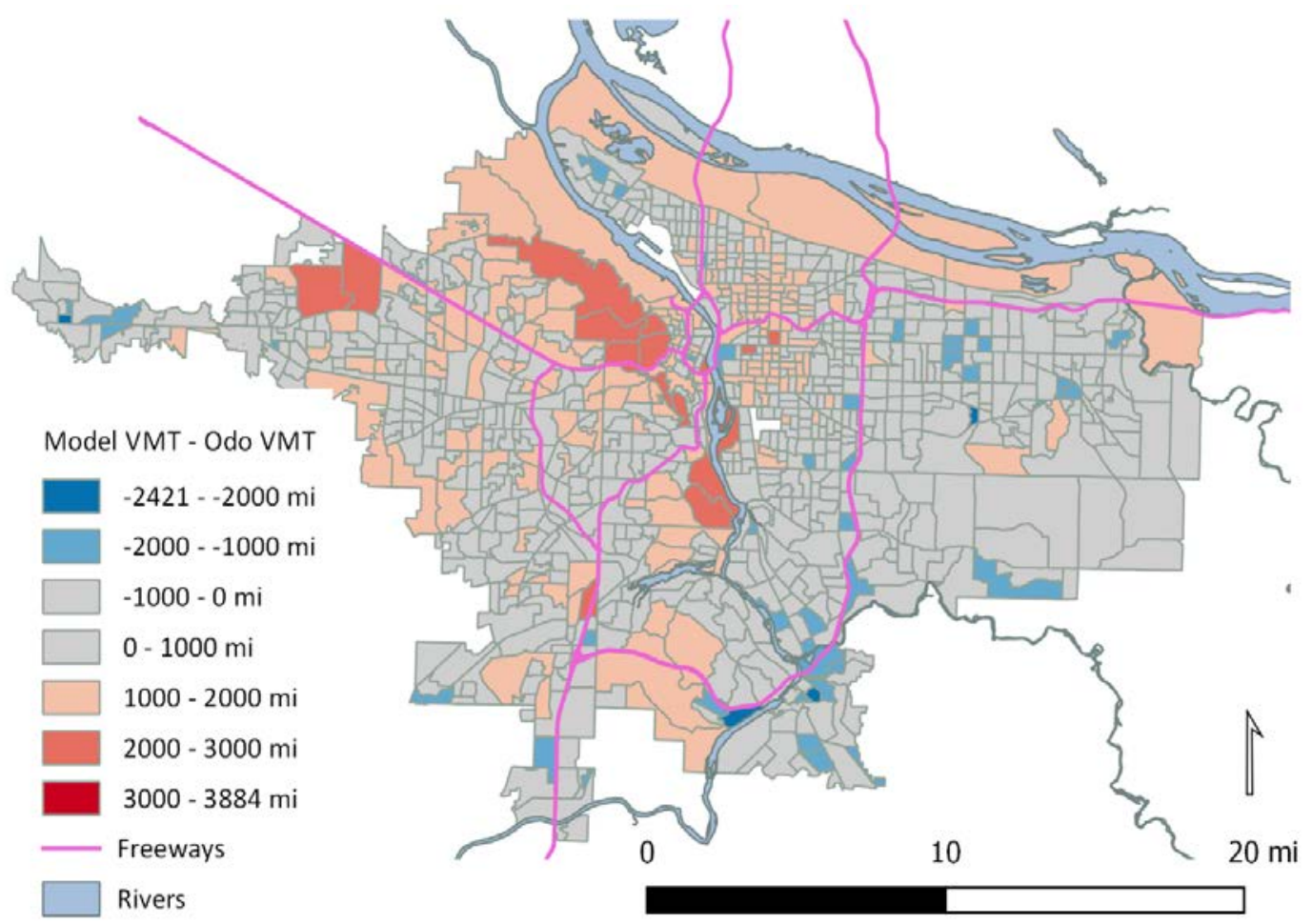




\section{Appendix C - Why race was not included in the model}

While initial iterations the model predicted differences in annual average vehicle VMT by race, the rate of increase with respect to income is roughly the same regardless of race. The final iteration of the model does not include race, as most of that variation in VMT is already captured by household income.

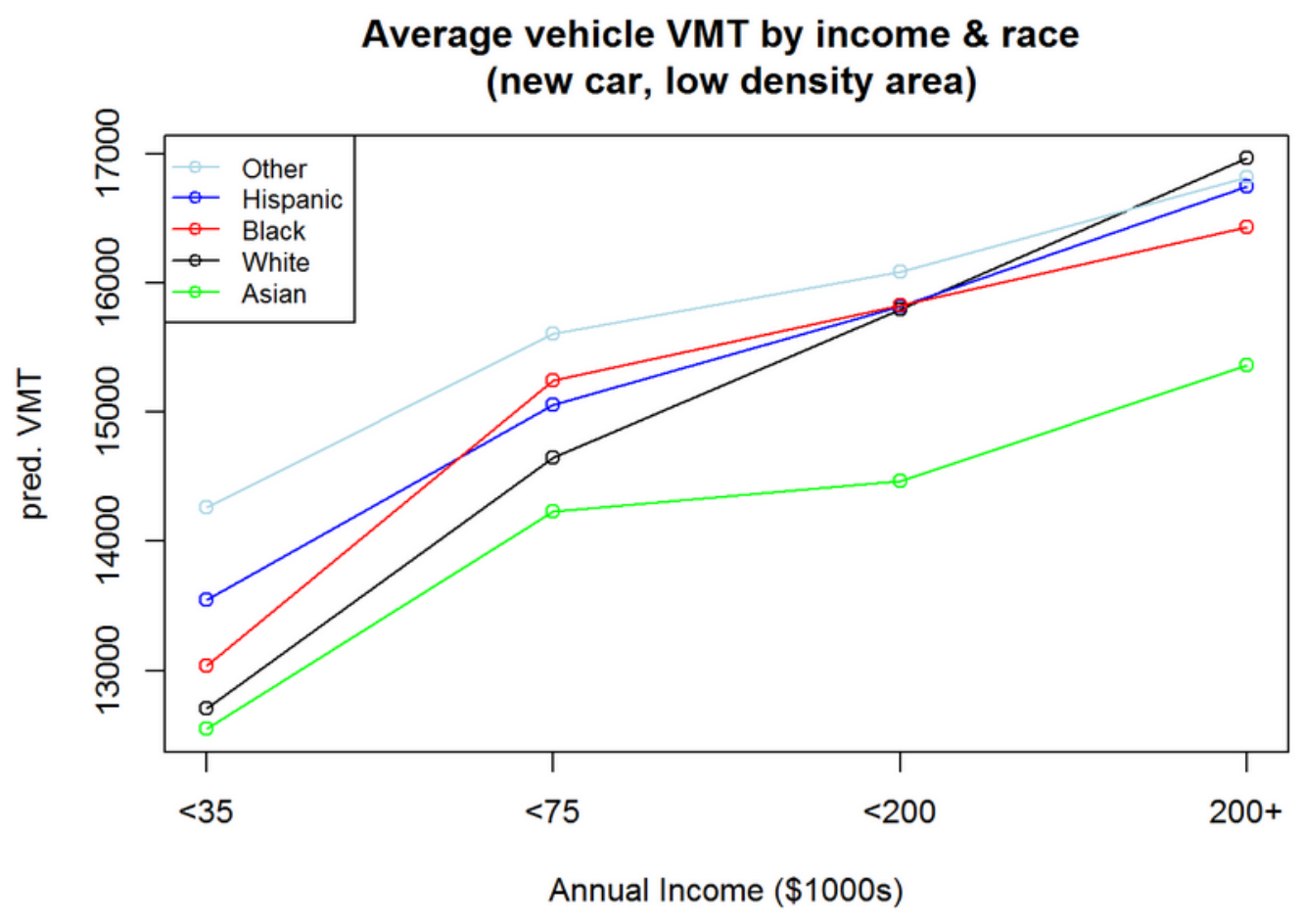




\section{Appendix D - Policy Scenario Details}

In the clunker, gas-guzzler, high VMT, and equity only scenarios, $10 \%$ of the existing ICE fleet would be replaced with new hybrids (non-plug-in) or EVs. We used EPA average fuel economy for all 2018 models to arrive at 35.6 MPG for hybrids and an effective 106.4 MPG for EVs used as replacements. For the density scenario, we chose two densification factors consistent with density gains in the region over the past fifteen years. Comparing 2016 ACS and 2000 Census data, the core county of the region (Multnomah, including the city of Portland) the average block group densified by $23.9 \%$.

Scenario 3 (high VMT) uses actual odometer data to identify high use vehicles. All other scenarios use predicted VMT from the model. In each case, scenarios were run on the entire DMV database of personal vehicles in Portland, except for the high VMT scenario, which had to be run only for the $\sim 50 \%$ of vehicles with valid odometer readings. Outcomes were tabulated to include VMT “rebound” effects. When older, gasoline vehicles are replaced with newer, alt fuel versions, the model supports existing literature that they will in most cases be used more. The one exception is for EVs up to three years newer than an existing gasoline vehicle; those vehicles are predicted to be used less (perhaps due to range anxiety or charging hassles).

Since detailed household information was not available in the DMV records, mean block group ACS data were used to estimate vehicle owners' income and household composition. 


\section{Appendix E - Policy Results Table}

\section{Results of policy scenarios replacing $10 \%$ of personal vehicle fleet or densifying region}

\begin{tabular}{|c|c|c|c|c|c|c|c|c|c|}
\hline \multirow[b]{3}{*}{ Scenario } & \multirow[b]{3}{*}{ Target } & & & & & \multicolumn{4}{|c|}{ Share to bottom $20 \%$ income areas } \\
\hline & & \multicolumn{2}{|c|}{$\begin{array}{l}\text { Total Fuel Saved } \\
\text { (million gals/yr) }\end{array}$} & \multicolumn{2}{|c|}{$\begin{array}{c}\% \text { of PDX Total } \\
\text { Saved }^{1} \\
\end{array}$} & \multicolumn{2}{|c|}{ Fuel Savings } & \multicolumn{2}{|c|}{$\begin{array}{c}\text { Mobility (VMT) } \\
\text { Increase }\end{array}$} \\
\hline & & Hybrid $^{2}$ & $\mathrm{EV}^{3}$ & Hybrid & $\mathrm{EV}$ & Hybrid & $\mathrm{EV}$ & Hybrid & $\mathrm{EV}$ \\
\hline \multirow{3}{*}{ Clunker } & $\begin{array}{l}\text { Region- } \\
\text { wide }\end{array}$ & -5.3 & 19.3 & $-1.3 \%$ & $4.6 \%$ & $25.3 \%$ & $20.2 \%$ & $21.7 \%$ & $21.7 \%$ \\
\hline & $\begin{array}{l}\text {...w/ equity } \\
\text { bias } \\
\end{array}$ & -6.5 & 20.5 & $-1.6 \%$ & $4.9 \%$ & $41.4 \%$ & $38.0 \%$ & $39.1 \%$ & $39.1 \%$ \\
\hline & \begin{tabular}{|l|} 
Oldest \\
Fleet Areas
\end{tabular} & 3.3 & 30.5 & $0.8 \%$ & $7.3 \%$ & $29.5 \%$ & $37.6 \%$ & $39.6 \%$ & $40.0 \%$ \\
\hline \multirow{3}{*}{$\begin{array}{l}\text { Gas } \\
\text { guzzler }\end{array}$} & \begin{tabular}{|l} 
Region- \\
wide
\end{tabular} & 16.1 & 44 & $3.8 \%$ & $10.5 \%$ & $14.0 \%$ & $15.9 \%$ & $18.5 \%$ & $19.2 \%$ \\
\hline & $\begin{array}{l}\text {...w/ equity } \\
\text { bias } \\
\end{array}$ & 13.9 & 41.1 & $3.3 \%$ & $9.8 \%$ & $32.4 \%$ & $34.1 \%$ & $36.0 \%$ & $36.4 \%$ \\
\hline & \begin{tabular}{|l} 
Lowest \\
MPG Areas \\
\end{tabular} & 5.3 & 33 & $1.3 \%$ & $7.8 \%$ & $16.5 \%$ & $25.5 \%$ & $29.2 \%$ & $30.3 \%$ \\
\hline \multirow{3}{*}{ High VMT } & \begin{tabular}{|l} 
Region- \\
wide
\end{tabular} & 16.9 & 53.9 & $4.0 \%$ & $12.8 \%$ & $16.1 \%$ & $17.2 \%$ & $18.1 \%$ & $18.8 \%$ \\
\hline & $\begin{array}{l}\text {...w/ equity } \\
\text { bias } \\
\end{array}$ & 15.9 & 53.2 & $3.8 \%$ & $12.7 \%$ & $34.2 \%$ & $34.7 \%$ & $35.2 \%$ & $35.7 \%$ \\
\hline & $\begin{array}{l}\text { Highest } \\
\text { VMT Areas }\end{array}$ & 6.1 & 35.4 & $1.5 \%$ & $8.4 \%$ & $12.2 \%$ & $16.4 \%$ & $18.0 \%$ & $18.5 \%$ \\
\hline \multirow[t]{2}{*}{$\begin{array}{l}\text { Equity } \\
\text { Only }\end{array}$} & $\begin{array}{l}\text { Lowest } \\
\text { Income } \\
\text { Areas }\end{array}$ & 2.4 & 28.1 & $0.6 \%$ & $6.7 \%$ & $81.7 \%$ & $83.9 \%$ & $84.8 \%$ & $85.2 \%$ \\
\hline & & $\begin{array}{l}+10 \% \\
\text { density }\end{array}$ & $\begin{array}{l}+20 \% \\
\text { density } \\
\end{array}$ & $\begin{array}{l}+10 \% \\
\text { density } \\
\end{array}$ & $\begin{array}{l}+20 \% \\
\text { density }\end{array}$ & & & & \\
\hline $\begin{array}{l}\text { Density } \\
\text { Only }\end{array}$ & $\begin{array}{l}\text { Region- } \\
\text { wide }\end{array}$ & 2.2 & 4.2 & $0.5 \%$ & $1.0 \%$ & & & & \\
\hline
\end{tabular}

$1 \%$ calculated out of total fuel used by all PDX registered personal use vehicles in our analysis set

${ }^{2}$ Hybrid replacement set to EPA average for all 2018 Hybrids (non-plug in) at 35.6 MPG combined

${ }^{3}$ EV replacement set to EPA average for all 2018 EVs (all electric) at 106.4 MPG combined 


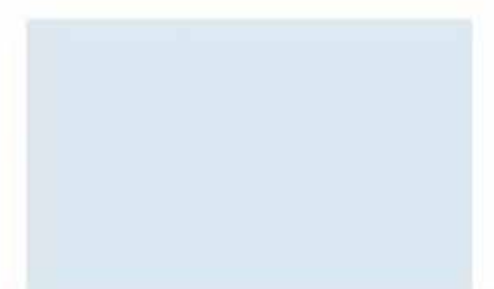

\section{HTEC \\ TRANSPORTATION RESEARCH \\ a and EDUCATION CENTER}

Portland State University

1900 S.W. Fourth Ave., Suite 175

Portland, OR 97201 